\title{
THE
}

\section{Descriptive oceanography during the Frontal Air-Sea Interaction Experiment: Medium- to large-scale variability}

\author{
George R. Halliwell \\ Peter C. Cornillon \\ University of Rhode Island, pcornillon@uri.edu \\ Kenneth H. Brink \\ Raymond T. Pollard \\ David L. Evans
}

See next page for additional authors

Follow this and additional works at: https://digitalcommons.uri.edu/gsofacpubs

Terms of Use

All rights reserved under copyright.

\section{Citation/Publisher Attribution}

Halliwell Jr., G. R., P. Cornillon, K. H. Brink, R. T. Pollard, D. L. Evans, L. A. Regier, J. M. Toole, and R. W. Schmitt (1991), Descriptive oceanography during the Frontal Air-Sea Interaction Experiment: Medium- to large-scale variability, J. Geophys. Res., 96(C5), 8553-8567, doi: 10.1029/91JC00100.

Available at: http://dx.doi.org/10.1029/91JC00100

This Article is brought to you for free and open access by the Graduate School of Oceanography at DigitalCommons@URI. It has been accepted for inclusion in Graduate School of Oceanography Faculty Publications by an authorized administrator of DigitalCommons@URI. For more information, please contact digitalcommons-group@uri.edu. 


\section{Authors}

George R. Halliwell, Peter C. Cornillon, Kenneth H. Brink, Raymond T. Pollard, David L. Evans, Lloyd A. Regier, John M. Toole, and Raymond W. Scmitt 


\title{
Descriptive Oceanography During the Frontal Air-Sea Interaction Experiment: Medium- to Large-Scale Variability
}

\author{
George R. Halliwell, JR., ${ }^{1}$ Peter Cornillon, ${ }^{2}$ Kenneth H. Brink, ${ }^{3}$ Raymond T. Pollard, ${ }^{4}$ \\ David L. Evans, ${ }^{5}$ Lloyd A. Regier, ${ }^{6}$ John M. Toole, ${ }^{3}$ and Raymond W. Schmitt ${ }^{3}$
}

\begin{abstract}
Medium- and large-scale oceanographic variability in the Sargasso Sea is examined during the Frontal Air-Sea Interaction Experiment (FASINEX), focusing primarily on processes that influence the formation of subtropical fronts. From Fall to Spring the mean meridional gradient of meridional Ekman transport in the Subtropical Convergence Zone (STCZ) enhances the meridional sea surface temperature $\left(T_{s}\right)$ gradients between $26^{\circ}$ and $32^{\circ} \mathrm{N}$. In the presence of this enhanced mean gradient, baroclinic eddies with zonal wavelengths of $\approx 800 \mathrm{~km}$ and periods of $\approx 200$ days exert the dominant influence on the formation of subtropical fronts at medium and large scales. These eddies generate westward propagating $T_{s}$ anomaly features with the same dominant wavelengths and periods. They are confined between $26^{\circ}$ and $32^{\circ} \mathrm{N}$ and have amplitudes that occasionally exceed $\pm 1{ }^{\circ} \mathrm{C}$. $T_{s}$ fronts tend to be found within bands $\approx 200 \mathrm{~km}$ wide that roughly follow the periphery of these anomaly features. Deformation in the horizontal eddy current field is primarily responsible for the existence of these frontal bands. The migration of the strong front originally bracketed by the FASINEX moored array was related to the westward propagation of the larger-scale eddy/anomaly/frontal-band pattern. The moored array was located within a warm-anomaly feature during most of the experiment, which produced exceptionally warm conditions in the upper ocean. These anomalies are confined between $26^{\circ}$ and $32^{\circ} \mathrm{N}$, not only because the relatively large seasonal mean $T_{s y}$ there allows horizontal eddy currents to force strong anomalies, but also because the baroclinic eddies with wavelengths of $\approx 800$ $\mathrm{km}$ and periods of $\approx 200$ days are confined to the STCZ. Large meridional variability exists in many properties of the eddy field, much of which can be traced to the influence of the Sargasso Sea mean current field on eddy variability.
\end{abstract}

\section{INTRODUCTION}

The Frontal Air-Sea Interaction Experiment (FASINEX) was designed to study air-sea interaction processes in the vicinity of an oceanic surface temperature front, specifically the subtropical front within the Sargasso Sea Subtropical Convergence Zone (STCZ), over wavelengths less than 100 $\mathrm{km}$. Information on the larger-scale background variability of the ocean relevant to the FASINEX measurements was also collected to aid in the interpretation of these measurements. In this paper the variability of sea surface temperature $\left(T_{s}\right)$ and surface temperature fronts over horizontal wavelengths of $O(100)$ to $O(1000) \mathrm{km}$ (henceforth referred to as medium- and large-scale variability) and periods of $O(100)$ days (henceforth referred to as low-frequency variability) is examined in the FASINEX region. Another goal is to connect the large-scale oceanographic climatology of the region described by Hanson et al. [this issue] to the smallerscale ocean measurements described in other papers in this issue.

\footnotetext{
${ }^{1}$ Division of Meteorology and Physical Oceanography, Rosenstiel School of Marine and Atmospheric Science, University of Miami, Miami, Florida.

${ }^{2}$ Graduate School of Oceanography, University of Rhode Island, Narragansett.

${ }^{3}$ Department of Physical Oceanography, Woods Hole Oceanographic Institution, Woods Hole, Massachusetts.

${ }^{4}$ Deacon Laboratory, Institute of Oceanographic Sciences, Wormley, Godalming, Surrey, England.

${ }^{5}$ Physical Oceanography Program, Office of Naval Research, Arlington, Virginia.

${ }^{6}$ Scripps Institution of Oceanography, La Jolla, California.

Copyright 1991 by the American Geophysical Union.
}

Paper number $91 \mathrm{JC} 00100$.

0148-0227/91/91JC-00100\$05.00
A brief review of properties of subtropical fronts determined from studies conducted prior to FASINEX is presented in section 2 . The medium- and large-scale variability of $T_{s}$, fronts, wind stress, and wind stress curl fields during FASINEX is then examined in section 3, focusing first on monthly mean properties, then on six 5-day intervals during FASINEX phase II. In section 4, dynamical processes responsible for the observed medium- and large-scale variability of upper ocean temperature and fronts are described, primarily synthesizing the results from several studies conducted as part of FASINEX.

\section{BACKGROUND}

Since the FASINEX region (Figure 1) is located in the southwestern part of the North Atlantic subtropical gyre, long-term mean flow due to the gyre circulation is expected to be toward the west and southwest, with speeds increasing toward the north and west as the Gulf Stream recirculation region is approached [e.g., Stommel et al., 1976; Olson et al., 1984]. However, the existence of a zonal band of mean eastward current in the Sargasso Sea a few degrees of latitude wide within and above the main thermocline has been documented in a number of studies, including those of Iselin [1936], Reid [1978], Ebbesmeyer and Taft [1979], Rossby et al. [1983], and Olson et al. [1984]. This eastward current is evident in the meridional cross sections of zonal geostrophic velocity, derived from the Levitus [1982] atlas, presented by Hanson et al. [this issue]. A similar eastward current, referred to as the Subtropical Countercurrent, has been documented in the western North Pacific STCZ [e.g., Uda and Hasunuma, 1969]. Long-term mean conditions in the upper ocean and at the air-sea interface are discussed in more detail by Hanson et al. [this issue].

The $T_{s}$ field imposed by surface vertical heat flux is 


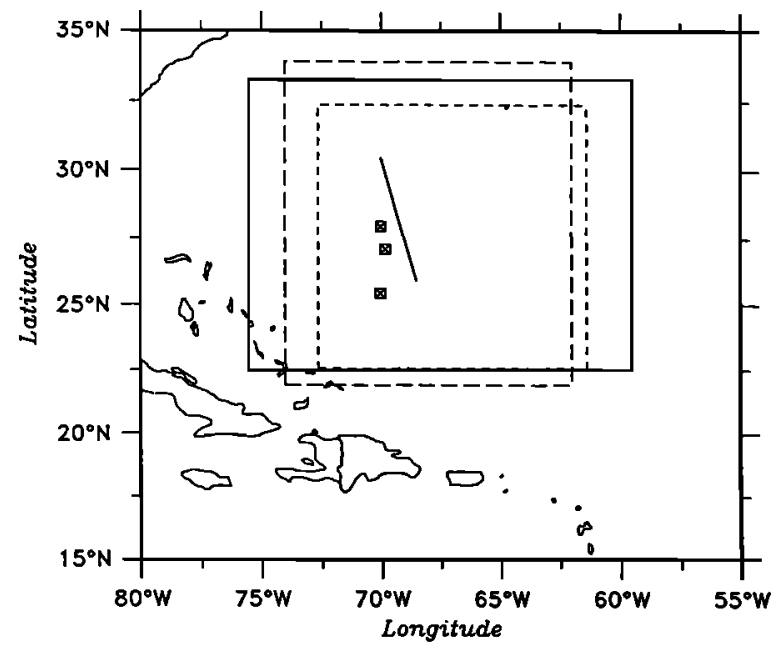

Fig. 1. Domains used for the analyses of medium- and largescale variability. The box outlined by short dashed lines was used for FASINEX $T_{s}$ analyses [Halliwell and Cornillon, 1990a] and frontal path analyses (E. Böhm et al., manuscript in preparation, 1991). The box outlined by solid lines was used for the long-term 1982-1988 analyses of $T_{s}$ [Halliwell et al., 1991]. The box outlined by long dashed lines is the $12^{\circ}$ by $12^{\circ}$ box used for the descriptive oceanic climatology presented by Hanson et al. [this issue]. The locations of FASINEX moorings (top) F1, (center) F2-F10, and (bottom) F12 are shown by the squares. The primary ship-ofopportunity track [Halliwell, 1991] is shown by the solid straight line.

dominated by very large wavelengths ( $>>1000 \mathrm{~km}$ ). Physical processes then act upon this imposed background $T_{s}$ field to generate surface temperature fronts a few kilometers wide. During winter, when the magnitude of the background $T_{s}$ gradient is relatively large, the fronts that form can have temperature jumps of up to $3^{\circ} \mathrm{C}$ within $10 \mathrm{~km}$, and they can exceed $1000 \mathrm{~km}$ in length [Voorhis and Hersey, 1964; Voorhis, 1969]. Such a front was selected for study during FASINEX. Physical processes generating these fronts act over several decades of wave number space, with their relative importance varying as a function of wave number and frequency. During summer, when the background $T_{s}$ gradient is small, surface temperature fronts are weak or nonexistent, and generally cannot be observed in satellite infrared images. However, studies conducted in the North Pacific STCZ [e.g., Roden, 1975; White et al., 1978] show that salinity fronts do not disappear in summer, and they also show that temperature fronts do not disappear in summer beneath the shallow mixed layer. Consequently, many of the physical processes responsible for winter frontogenesis must also operate during summer, with the absence of strong summer $T_{s}$ fronts resulting largely from the weak background surface gradient.

In climatological mean $T_{s}$ fields, the surface subtropical front appears as a zonal band of enhanced meridional $T_{s}$ gradient that is a few degrees of latitude wide [e.g., Roden, 1975]. This broad frontal band will be referred to here as the subtropical frontal zone (SFZ) to distinguish it from actual fronts. White et al. [1978] used historical temperature data to describe the seasonal and interannual large-scale variability of the North Pacific SFZ from 1954 to 1974. Based on estimates of the zonal $0 / 200$ dbar geostrophic shear, he determined that the frontal zone near the western end of the
North Pacific was strongest (had the largest magnitude meridional temperature and density gradients) and farthest north in spring, and was weakest and farthest south in fall. The magnitude of this seasonal variability decreased toward the east. Significant interannual variability in the seasonal cycle was also documented, with the SFZ tending to be stronger during El Niño years. A similar detailed study of the western North Atlantic SFZ and its variability at these wavelengths and periods did not exist prior to FASINEX. In the monthly meridional cross sections of temperature in the Sargasso Sea presented by Schroeder [1965], the frontal zone was located between $25^{\circ}$ and $30^{\circ} \mathrm{N}$ from October through May. The relatively weak near-surface meridional $T_{s}$ gradients, along with the temperature perturbations due to the presence of baroclinic eddies, made it difficult to identify the frontal zone during summer.

In the presence of mean negative meridional temperature gradient near the surface, the mean negative meridional gradient of meridional Ekman transport that exists in the STCZ between the westerlies to the north and the trade winds to the south has long been considered a primary generation mechanism for subtropical fronts, and theoretical studies of this mechanism have been presented by De Szoeke [1980], Welander [1981], and Cushman-Roisin [1981]. For simplicity, this mechanism will be referred to as Ekman frontogenesis. Roden [1975] showed how the mean SFZ in the Pacific was located near the latitude where the negative meridional gradient of mean meridional Ekman transport was largest. The significance of this process is also confirmed by other observational studies [e.g., Roden, 1980; Roden and Paskausky, 1978]. Other processes may also be important, however. For example, Cushman-Roisin [1981] points out that the cold (warm) wind-driven heat advection tends to decrease (increase) the magnitude of the temperature jump across the mixed layer base to the north (south) of the SFZ. This will influence the meridional distribution of mixed layer entrainment, and thus the strength and meridional symmetry of the SFZ. Even more significant are the models of De Ruijter [1983] and Cushman-Roisin [1984] that illustrate two mechanisms by which horizontal gradients of vertical heat fluxes can lead to frontogenesis. Also, the numerical model of Takeuchi [1984] was capable of generating a SFZ in the absence of Ekman frontogenesis, indicating that other (unidentified) processes must be producing frontogenesis in the model.

As smaller space and time scales are resolved by data, the observed structure and variability of fronts in the STCZ becomes much more complex. This is illustrated for space scales in the North Pacific STCZ by the superposition of salinity maps created from data sets with different resolution by Niiler and Reynolds [1984]. At wavelengths of $\mathrm{O}(1000)$ $\mathrm{km}$, the enhanced salinity gradients associated with the SFZ appeared as a broad zonal band, just as for temperature. As wavelengths down through $\mathrm{O}(100) \mathrm{km}$ to $O(10) \mathrm{km}$ become resolved, highly convoluted isohalines and salinity fronts appear in the maps within the SFZ. Within frontal zones such as the SFZ, one or more fronts are often observed, and these fronts can at times be highly convoluted. These characteristics of frontal variability were observed in the eastern North Pacific SFZ by Samelson and Paulson [1988]. Fedorov [1983] has discussed this scale dependence of frontal properties.

Although the FASINEX region was located within a 
broad, zonally oriented minimum of eddy energy [e.g., Dantzler, 1977; Emery, 1983; Robinson et al., 1983], the eddy field at the FASINEX site, which has been studied in a number of earlier experiments [e.g., MODE Group, 1978; Taft et al., 1986; Chiu and Desaubies, 1987] is still strong enough to substantially influence subtropical fronts. Voorhis et al. [1976] demonstrated how horizontal circulation around mesoscale $(\mathrm{O}(100) \mathrm{km})$ baroclinic eddies influenced the location and strength of $T_{s}$ fronts during MODE. These currents advected existing fronts, and the deformation present in this current field produced local regions of frontogenesis and frontolysis, strengthening some segments of subtropical fronts while weakening or dissipating other segments. Submesoscale $(\mathrm{O}(10) \mathrm{km})$ eddies also significantly affected subtropical fronts [Voorhis and Bruce, 1982]. Eddy variability is therefore largely responsible for the complex horizontal spatial structure of salinity and temperature observed in high-resolution maps.

\section{Medium- and Large-Scale Variability ObServed DURING FASINEX}

\subsection{Data Sets}

Several different data sets were generated to study medium- to large-scale variability. Analyses performed during the FASINEX period [Halliwell and Cornillon, 1989, 1990a, b] were performed using $T_{s}$ maps derived from 5-day composite advanced very high resolution radiometer (AVHRR) infrared images by binning and averaging all $T_{s}$ estimates not contaminated by clouds onto a $0.25^{\circ}$ resolution grid, then spatially smoothing (necessary because of the data lost due to clouds) to resolve wavelengths greater than $200-300 \mathrm{~km}$. The large-scale distribution of fronts during 1982-1986 was described by Böhm [1988] and E. Böhm et al. (manuscript in preparation, 1991), using frontal paths digitized directly from AVHRR images. The domain for both of these data sets was the $11^{\circ}$ longitude by $10^{\circ}$ latitude box enclosed by the short dashed lines in Figure 1. Longer-term studies of $T_{s}$ variability [Halliwell et al., 1991] were performed using 5-day maps between 1982 and 1988, derived from 5-day composite AVHRR images by using objective analysis to fill gaps caused by clouds, then filtering in both space and time to focus on wavelengths greater than $200 \mathrm{~km}$ and periods greater than $\mathbf{5 0}$ days. Longer-term studies of eddy forcing of $T_{s}$ variability (G. R. Halliwell, Jr., Y.-J. Ro, and P. Cornillon, Westward propagating SST anomalies and baroclinic eddies in the Sargasso Sea, 1982-1988, submitted to the Journal of Physical Oceanography, 1991) were performed using 5-day sea surface elevation ( $\eta$ ) maps between November 19, 1986, and October 14, 1988, created by objective analysis of Geosat data processed as described by Y.-J. Ro and $\mathrm{P}$. Cornillon (How to reduce the geoid error from Geosat altimeter by use of EOF technique, submitted to Journal of Atmospheric and Oceanic Technology, 1991). The longerterm studies of $T_{s}$ variability and eddy forcing were conducted within the $16^{\circ}$ longitude by $12^{\circ}$ latitude box enclosed by the solid lines in Figure 1, although the $\eta$ maps were confined to the region east of $71.5^{\circ} \mathrm{W}$. Analyses of the FASINEX ship-of-opportunity expendable bathyohermograph cross sections [Evans et al., 1986] made along the approximate path shown in Figure 1 were described by G. R. Halliwell, Jr. (Ship-of-opportunity cross sections of the western North Atlantic subtropical convergence zone, submitted to the Journal of Geophysical Research, 1991). Fleet Numerical Oceanography Center (FNOC) wind fields were used in all of the above studies, with 5-day averaged maps of wind and wind stress created at the same times as the $T_{s}$ maps.

\subsection{Monthly Averaged Fields}

The 5-day $T_{s}$ maps created for the long-term studies are used here to describe the medium- and large-scale upper ocean variability during FASINEX. To facilitate the comparison between the maps presented here and the climatological maps presented by Hanson et al. [this issue], the fields described in this section are displayed in the same $12^{\circ}$ by $12^{\circ}$ box used by Hanson et al. $\left(74^{\circ}-62^{\circ} \mathrm{W}, 22^{\circ}-34^{\circ} \mathrm{N}\right.$; Figure 1$)$.

Monthly mean $T_{s}$ fields (Figure 2 ) are too smooth to resolve fronts, so the SFZ was the dominant frontal feature visually evident. Between January and May the SFZ was generally found between $25^{\circ}$ and $32^{\circ} \mathrm{N}$. During January, a large southward (northward) meander of the SFZ existed to the west (east) of the FASINEX moorings. At this time, the SFZ crossed the FASINEX central mooring array with a SW-NE orientation (Figure 2). This meander pattern shifted westward with time, with the southward meander disappearing off the western end of the domain and the northward meander moving over the FASINEX moorings by April. By June, after most of the rapid seasonal warming had occurred, the SFZ weakened and shifted to the north of $30^{\circ} \mathrm{N}$, while the large-scale meanders disappeared.

Monthly composites of frontal paths from Böhm [1988] (Figure 3 ) revealed a much more complex frontal pattern than the monthly averaged $T_{s}$ maps. Fronts were found throughout the domain except for May and June, when strong solar heating made them more difficult to detect, especially in the southern part. Fewer fronts were observed during January than in the following 3 months owing to relatively extensive cloud cover. Prior to June, frontal paths tended to be found within bands that were typically $\approx 200 \mathrm{~km}$ wide and had characteristic separation scales of up to several hundred kilometers. These bands can be thought of as regions where, over a time interval of about 1 month, there is a greater probability of encountering a persistent $T_{s}$ front than elsewhere. The bands were best developed during February, when several well-defined bands surrounded regions that were nearly free of fronts. The bands were more diffuse in the other months. The paths of individual fronts within the bands were often highly convoluted over distances of $10-100 \mathrm{~km}$. One front was usually present within a band at a given time, but segments of these bands occasionally contained broken and multiple fronts. The strength and location of fronts often changed dramatically within a period of one to several days, consistent with the submesoscale variability observed by Voorhis and Bruce [1982]. In contrast, frontal bands evolved much more slowly.

The monthly averaged vector wind stress field (Figure 4) differed substantially from month to month. Monthly averaging was sufficient to resolve the mean westward wind stress at $22.5^{\circ} \mathrm{N}$ during all months owing to the relative persistence of the trade winds, but it was insufficient to resolve the mean eastward stress expected in the northern part of the domain because the very strong synoptic-scale ( 2 days to 2 weeks) variability in the westerlies was not averaged out. Consequently, the large-scale wind stress pattern responsible for Ekman frontogenesis can only be detected by averaging the wind stress field over a period 


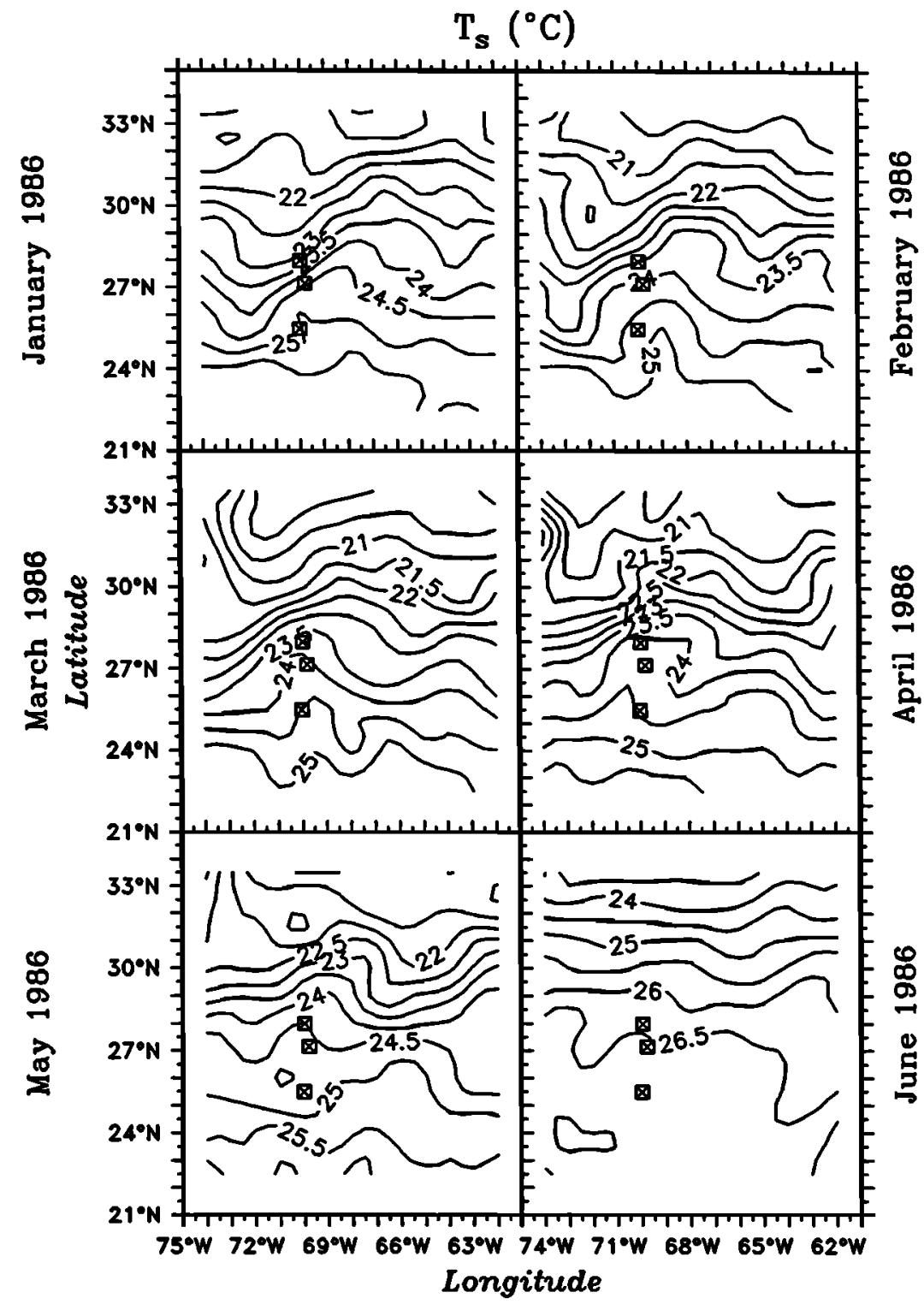

Fig. 2. Monthly averaged maps of $T_{s}$ within the $12^{\circ}$ by $12^{\circ}$ box during FASINEX, derived from $T_{s}$ maps created for the long-term analyses (section 3.1). The locations of FASINEX moorings (top) F1, (center) F2-F10, and (bottom) F12 are shown by the squares in each panel.

substantially in excess of 1 month. Wind stress curl is expected to be negative in the STCZ, and this was generally true during FASINEX except within the northern part of the box (Figure 4). Again, averages over a period substantially in excess of 1 month are necessary to resolve accurately the mean negative curl pattern. Atmospheric variability was dominated by wavelengths larger than the analysis domain, but wavelengths less than several hundred kilometers are poorly resolved in the FNOC fields [Halliwell and Cornillon, 1990a].

We averaged the fields in Figures 2 and 4 and also compiled the frontal paths in Figure 3 over January through April (Figure 5) to see if this was adequate to detect the expected relationship between the SFZ and the large-scale wind stress field during FASINEX. The mean SFZ was evident as the predominantly zonal band of relatively large $T_{s}$ gradient magnitude centered between the $22^{\circ}$ and $23^{\circ} \mathrm{C}$ isotherms. The SFZ was centered near $27^{\circ}-28^{\circ} \mathrm{N}$ at the western end of the domain, near $29.5^{\circ}-30.5^{\circ} \mathrm{N}$ in the center of the domain, and near $29^{\circ}-30^{\circ} \mathrm{N}$ at the eastern end. The mean stress had an eastward (westward) component in the northern (southern) part of the domain, as expected (Figure 5). The transition from eastward to westward component occurred near $27.5^{\circ} \mathrm{N}$ at the western end of the domain, and about halfway between $27.5^{\circ}$ and $30^{\circ} \mathrm{N}$ at the eastern end, agreeing qualitatively with the average WSW-ENE trend of the SFZ evident in the $T_{s}$ field. This suggests that Ekman frontogenesis contributes to the generation of the SFZ. In the eastern half of the domain, the largest negative wind stress curl existed substantially farther to the north $\left(31^{\circ}-\right.$ $\left.33^{\circ} \mathrm{N}\right)$ than it did in the western half $\left(23^{\circ}-26^{\circ} \mathrm{N}\right)$ (Figure 5). A visual relationship between the curl pattern and the SFZ is not evident.

In contrast to the single frontal zone evident in the $T_{s}$ field, frontal paths were very widely distributed throughout the entire $12^{\circ}$ box in the 4-month compilation (Figure 5). The 


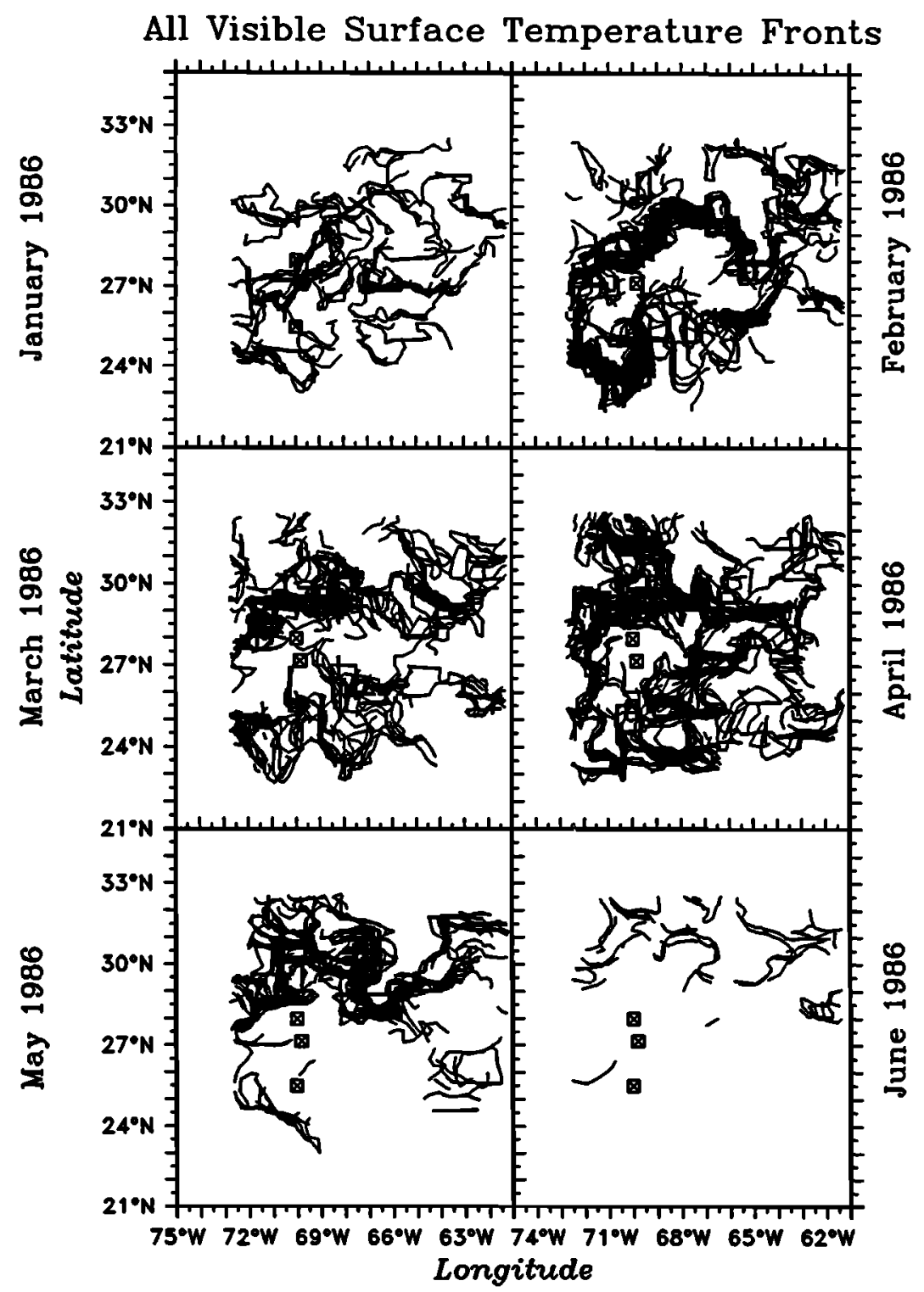

Fig. 3. Monthly composites of frontal paths during FASINEX obtained from Böhm [1988]. Although they are plotted in the $12^{\circ}$ by $12^{\circ}$ box, frontal paths were only traced in the smaller FASINEX analysis domain. The locations of FASINEX moorings (top) F1, (center) F2-F10, and (bottom) F12 are shown by the squares in each panel.

banded structure evident in most monthly compilations was only slightly evident owing to the temporal evolution of bands, along with the fact that all fronts are not confined to the bands. When frontal paths are compiled over a time interval sufficiently long to obtain a stable estimate of the large-scale wind field responsible for Ekman frontogenesis, the resulting distribution of frontal paths is no longer related to this pattern. Other processes must exert a strong influence on the distribution of fronts.

\subsection{Phase II Fields}

Six gap-free 5-day infrared images spanning the Phase II period were created by filling cloud-contaminated portions of $4 \mathrm{~km}$ resolution images using objective analysis (Plate 1). Cross-hatching denotes these interpolation regions in Plate 1. All frontal paths visible during each 5-day interval have been overlaid onto these images.
The tendency for fronts to appear in persistent bands is very evident in the 5-day path composites (Plate 1), since FASINEX Phase II was conducted during the period when the frontal bands were most clearly developed. The large space-time variability in the number of frontal paths within different segments of the frontal bands is primarily due to uneven sampling caused by cloudiness. The locations of these frontal bands are generally marked by $T_{s}$ jumps in the images (Plate 1). The unusually warm region that was moving over the FASINEX moorings during this period is also evident. There is an indication that frontal variability within the bands during Phase II was temporally modulated. Frontal variability was very small between February 25 and March 1 (Plate 1d), with a long single coherent front generally present within each band that migrated no more than $20-30 \mathrm{~km}$. In contrast, the variability was much larger between March 7 and 11 (Plate 1f), with paths migrating over crossband 


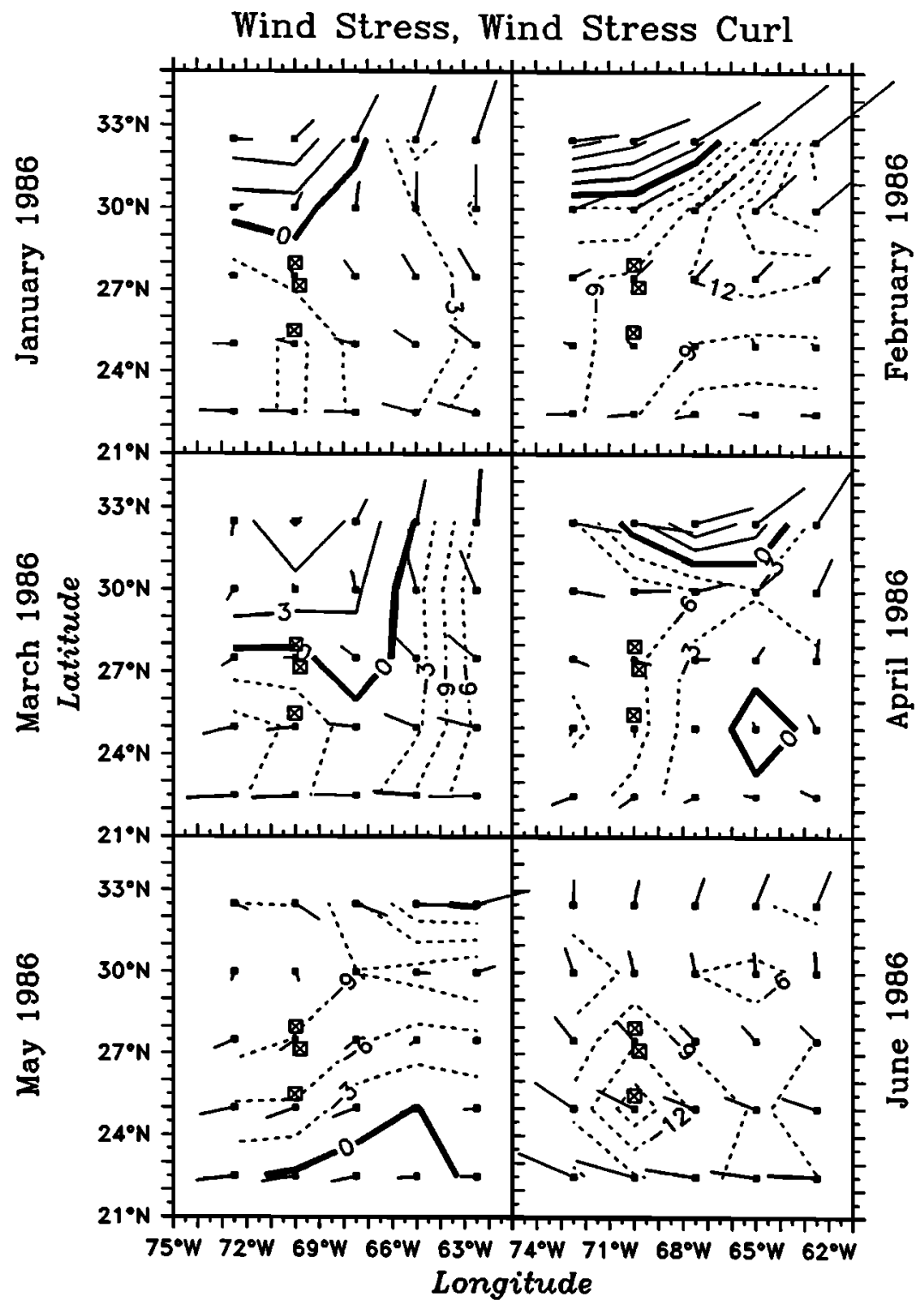

Fig. 4. Maps of the monthly mean wind stress vectors and of the monthly mean wind stress curl field, derived from FNOC wind fields in the $12^{\circ}$ by $12^{\circ}$ box. The locations of FASINEX moorings (top) F1, (center) F2-F10, and (bottom) F12 are shown by the squares in each panel. Dashed contours indicate negative values in this and all subsequent countour plots.

distances up to $\approx 100 \mathrm{~km}$, and with broken or multiple fronts present in some segments of the frontal bands.

\section{Dynamical Processes}

\subsection{Influence of Ekman Frontogenesis}

Halliwell and Cornillon [1990b] attempted to detect statistically the response of both $T_{s}$ and the SFZ to the large-scale Ekman transport field. The influence of Ekman transport alone on low-frequency $T_{s}$ variability can be derived from a slab mixed layer model [e.g., Frankignoul, 1985]:

$\rho_{0} c h\left\langle T_{s t}\right\rangle=-c\left(\frac{\langle\tau\rangle}{f} \times \mathbf{k}\right)\left\langle\nabla T_{s}\right\rangle-c\left(\left(\frac{\boldsymbol{\tau}^{\prime}}{f} \times \mathbf{k}\right) \cdot \nabla T_{s}^{\prime}\right\rangle$,

where the subscript $t$ denotes time derivative, $f$ is the Coriolis parameter, $\rho 0$ is the water density (assumed constant), $c$ is the specific heat at constant pressure, $h$ is the mixed layer thickness (assumed constant), $\mathbf{k}$ is the vertical unit normal vector, $\nabla$ is the horizontal gradient operator, and $\tau$ is the wind stress. The primes denote synoptic-scale variability, while the angle brackets denote temporal averaging over a time interval longer than synoptic. The terms are given in units of the temporal change of heat content per unit area. The nonlinear influence of the synoptic-scale fluctuations on low-frequency $T_{s}$ variability through the rightmost term of (1), which Paduan and De Szoeke [1986] demonstrated to be potentially significant in the mid-latitude westerlies, could not be accurately evaluated using 5-day maps of $T_{s}$ and wind stress. The influence of horizontal Ekman transport divergence on the entrainment rate at the mixed layer base has also been neglected, because it cannot be quantified without knowledge of the temperature jump across the mixed layer base. Despite the neglect of these potentially important influences, and despite the assumption 


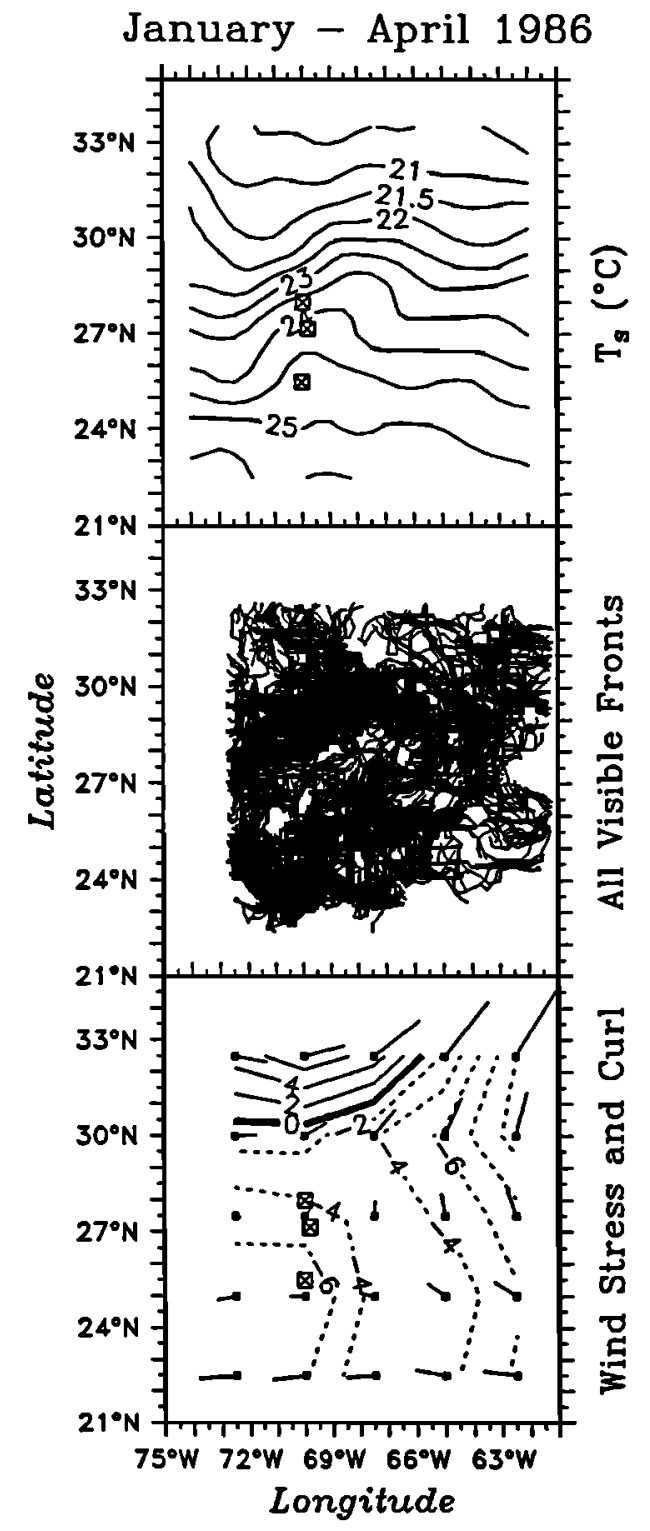

Fig. 5. (Top) The map of mean $T_{s}$, (center) the composite of all frontal paths, and (bottom) the map of mean wind stress curl along with mean wind stress vectors for January through April in the $12^{\circ}$ by $12^{\circ}$ box. The locations of FASINEX moorings (top) F1, (center) F2-F10, and (bottom) F12 are shown by the squares in each panel.

of constant $h$, useful results were obtained by analyzing the balance given by the first two terms of (1), referred to as the time derivative and Ekman terms [Halliwell and Cornillon, $1990 b]$.

Calculations were performed over the period between mid-January and mid-May 1986, which is prior to the onset of rapid seasonal warming and a period when the assumption of constant $h$ was not too unreasonable (Halliwell, submitted manuscript, 1991). Averaging over 4 months was also required to obtain a stable estimate of the large-scale "mean" wind stress pattern responsible for Ekman frontogenesis, as discussed in section 3.2. Four-month averaged maps of the time derivative and Ekman terms (Figure 6) show that they were spatially uncorrelated with each other. The averaged time derivative of $T_{s}$ equals the final minus initial $T_{s}$ field, and the contribution of the seasonal cycle to this term was small because the seasonal minimum of $T_{s}$ occurred near the middle of the 4-month interval. The mean time derivative term was dominated by a relatively large-scale anisotropic banded structure, with the major axis oriented SW-NE. In contrast, the Ekman term qualitatively resembled the theoretically expected pattern, producing cooling in the north due to southward transport and warming in the south due to northward transport (Figure 6). The time derivative term of (1) was about 3 times larger in magnitude than the Ekman term. The Ekman term was acting to maintain the SFZ during FASINEX, but other processes obviously exert the dominant influence on $T_{s}$ at the scales resolved in Figure 6.

To test if the relationship between these two terms is detectable at very large zonal scales, the two terms graphed in Figure 6 were zonally averaged across the entire analysis domain [Halliwell and Cornillon, 1990b]. These zonally averaged terms, along with zonally averaged $T_{s}$, are graphed as a function of latitude in Figure 7 , with mean meridional trends removed to emphasize their meridional structures. The zonally averaged subtropical front is confined between about $28.5^{\circ}$ and $31.5^{\circ} \mathrm{N}$, with the largest negative 4-month mean of zonally averaged $T_{s y}$ located at $29.4^{\circ} \mathrm{N}$. From the time derivative term, a latitude band existed between about $28^{\circ}$ and $29^{\circ} \mathrm{N}$, roughly $1^{\circ}$ south of the largest negative mean zonally averaged $T_{s y}$, where the negative gradient increased in magnitude over the 4-month interval. The zonally averaged SFZ was therefore tending to shift southward with time during this interval [Halliwell and Cornillon, 1990b]. Although the two terms in Figure 6 had very dissimilar twodimensional structure within the analysis domain, the zonally averaged terms had some similarities in meridional structure (Figure 7). In particular, the zonally averaged Ekman term was acting to increase the magnitude of negative zonally averaged $T_{s y}$ most rapidly between about $28^{\circ}$ and $29^{\circ} \mathrm{N}$, the latitude band where the maximum rate of change was actually observed. However, the Ekman term did underestimate the magnitude of this rate of change. The similarities in the meridional structure of the two terms are only suggestive of the SFZ responding to Ekman frontogenesis. A more extensive data set must be analyzed to validate this relationship statistically and also to determine if other processes such as those in the frontogenesis models of Cushman-Roisin [1984] and De Ruijter [1983] significantly influence the SFZ.

\subsection{Westward Propagating $T_{s}$ Anomaly Features}

The westward propagating $T_{s}$ anomaly features identified by Halliwell and Cornillon [1989] were responsible for the apparent westward shift of the wavy isotherm pattern in Figure 2 (section 3.2), and it was the propagation of these features that masked the influence of the large-scale Ekman transport field on $T_{s}$ and the SFZ. To illustrate the structure of these features, 5-day anomaly maps of $T_{s}\left(T_{s a}\right)$ were produced using the $T_{s}$ maps created for the long-term analyses by first calculating and removing the 7-year average seasonal cycle. A new set of anomaly maps $\left(T_{s a}^{\prime}\right)$ were then produced by removing linear trends from each $T_{s a}$ map. Maps of $T_{s a}^{\prime}$ for the 5-day time intervals centered on January 13 and March 14, 1986 (Figure 8) show that the magnitudes of the anomaly features sometimes exceeded $\pm 1^{\circ} \mathrm{C}$, and that the features were anisotropic, with a SW-NE major axis orientation. The characteristic wavelength and periods of 


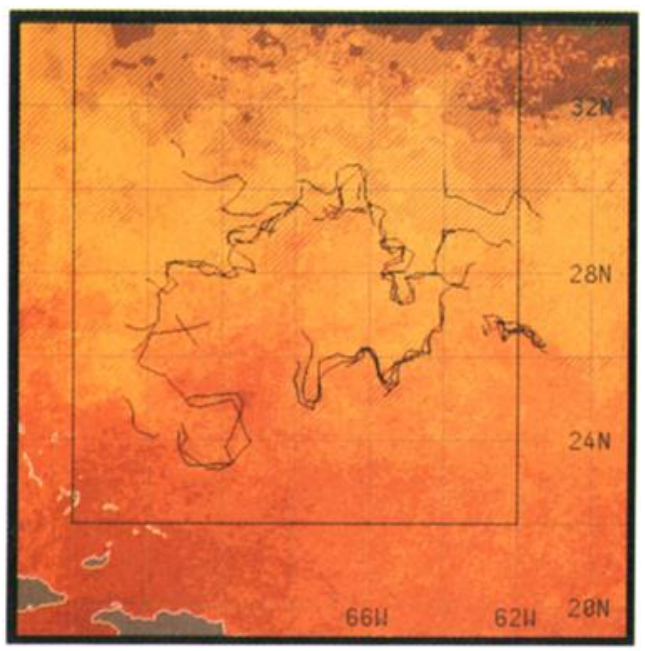

a. 10-14 February 1986

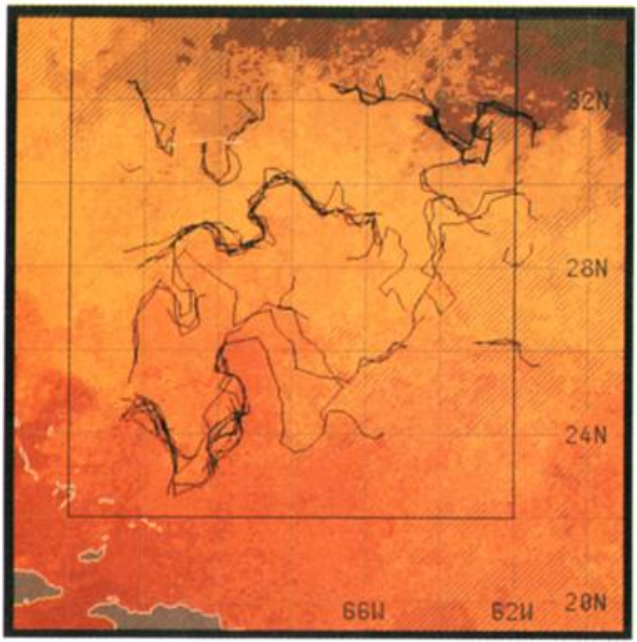

c. 20-24 February 1986

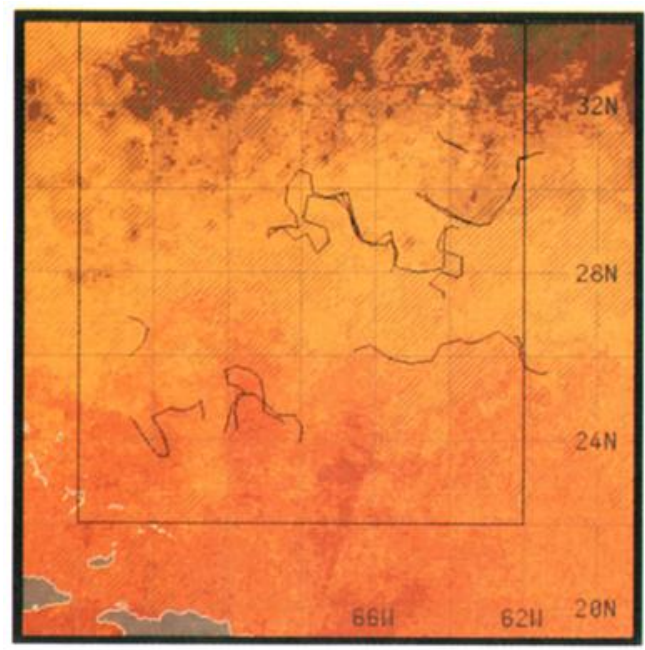

e. 2-6 March 1986

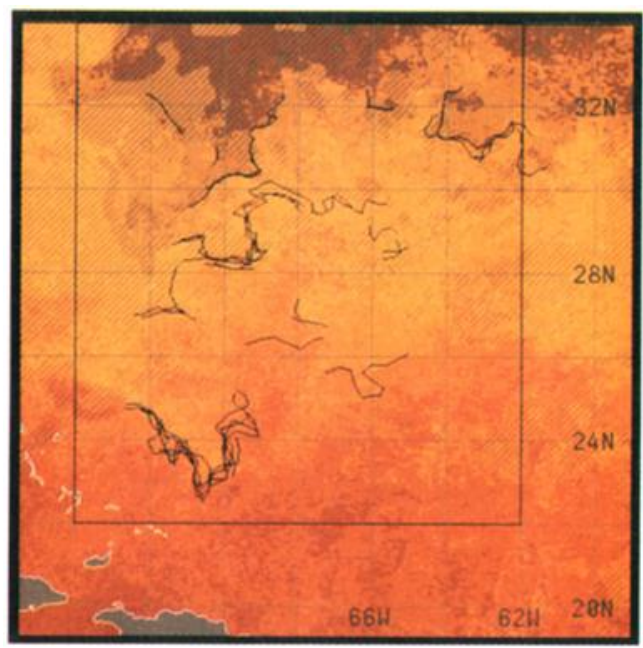

b. $15-19$ February 1986

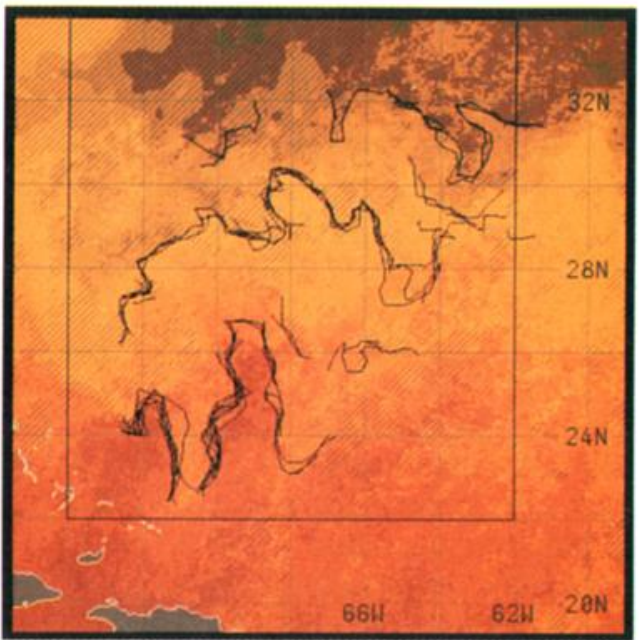

d. 25 February -1 March 1986

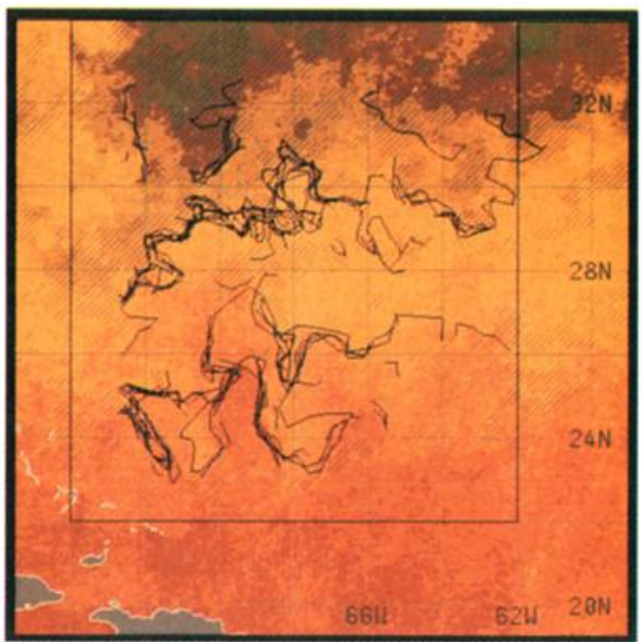

f. 7-11 March 1986

Plate 1. Five-day composite AVHRR images, with all frontal paths observed within each time interval superimposed, during FASINEX Phase II. Diagonal crosshatching outlines regions where data were contaminated by clouds and replaced by estimates using three-dimensional optimum interpolation. The $12^{\circ}$ by $12^{\circ}$ box used in Figures 2 through 5 is outlined. 


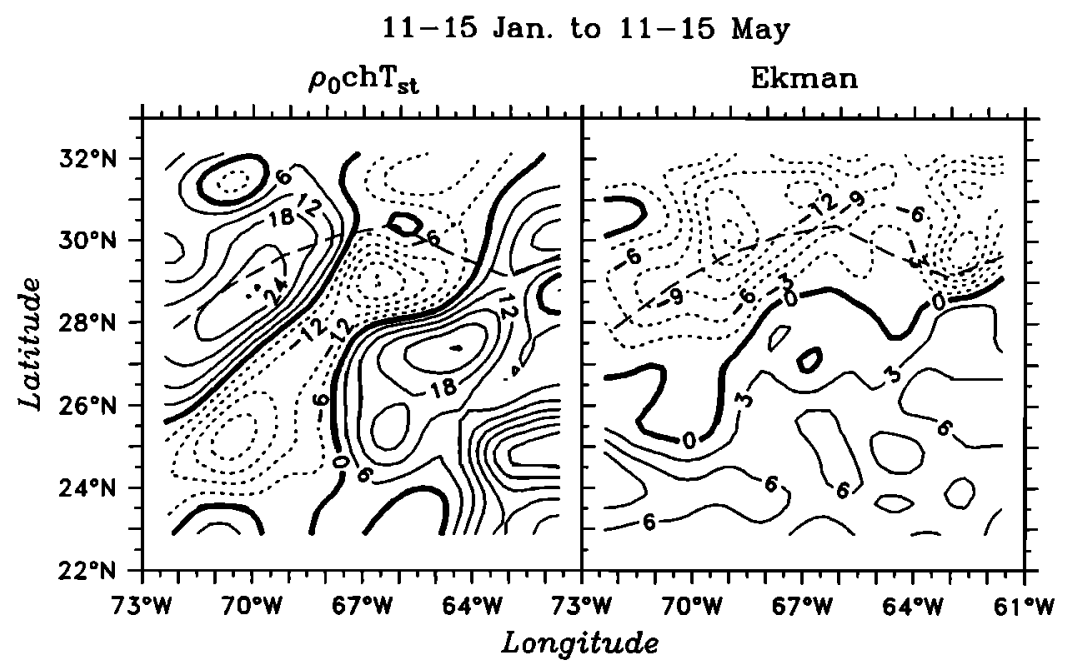

Fig. 6. Contour plots of the first two terms (the time derivative and Ekman terms) of equation (1) averaged between mid-January and mid-May 1986 within the FASINEX analysis domain (Figure 1), using the $T_{s}$ maps created for the FASINEX analyses (section 3.1). The latitude of maximum $\left|\nabla T_{s}\right|$ across the domain associated with the SFZ is traced by the long dashed line. (Adapted from Halliwell and Cornillon [1990b, Figure 2]).

these features were $\approx 800 \mathrm{~km}$ (minor axis direction) and $\approx 200$ days [Halliwell and Cornillon, 1989; Halliwell et al., 1991]. They propagated in a predominantely westward direction at $3-4 \mathrm{~km} \mathrm{~d}^{-1}$. It is evident from the January 13 map that the central FASINEX mooring array was deployed between two strong anomaly features: a warm feature located to the east and northeast and a cold feature located to the west and northwest. By March, these features had shifted westward, so that the FASINEX moorings were located well within the warm feature.

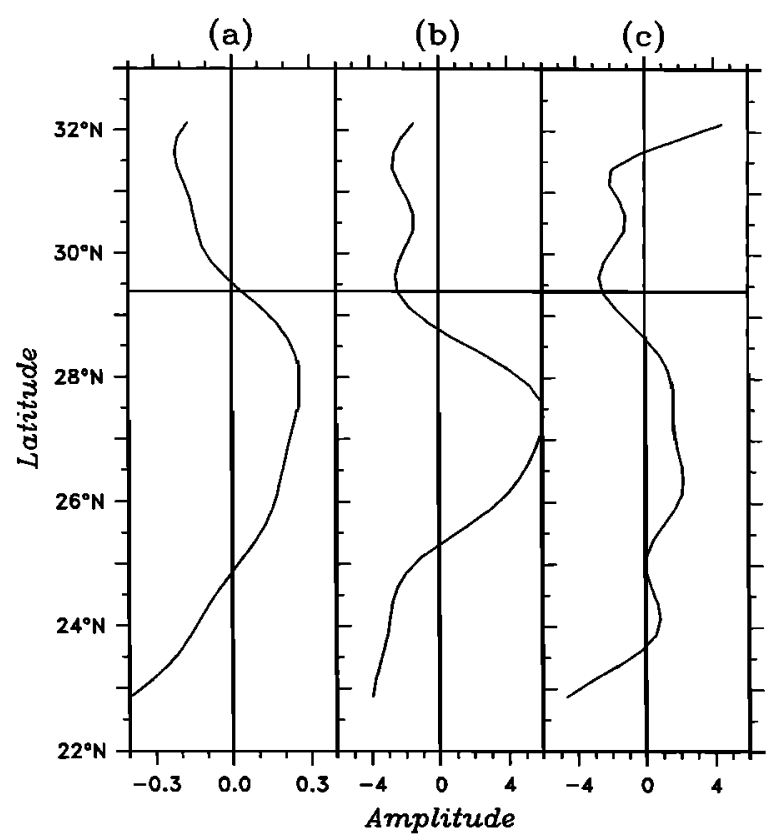

Fig. 7. (a) Zonal averages of $T_{s}$, along with (b) the time derivative and (c) the Ekman term contoured in Figure 6, with mean meridional trends removed. The latitude of maximum negative mean zonally averaged $T_{s y}$ in panel $a$, assumed to be the central latitude of the zonally averaged SFZ, is shown by the horizontal solid line. [From Halliwell and Cornillon [1990b, Figure 7].
The 4-month averaged time derivative term (Figure 6) had approximately the same major axis orientation (SW-NE) as the $T_{s a}^{\prime}$ field (Figure 8). The westward march of these features can account for the structure and magnitude of this term, since the averaging interval was close to one-half period. It was thus the physical processes generating the westward propagating anomaly features that were primarily responsible for masking the influence of Ekman transport on the SFZ. Zonally averaging the two terms in Figure 6 may have exposed a relationship between them because they were averaged over two to three anomaly features, largely cancelling their influence.

A contour plot of $T_{s a}^{\prime}\left(x, y_{0}, t\right)$ prepared from the 7-year data set illustrates the life history of the FASINEX anomaly features at $y_{0}=28^{\circ} \mathrm{N}$ (Figure 9). Westward propagation is visually evident from October 1985 through June 1986. In particular, the cold and warm features located near the FASINEX moorings in early 1986 (Figure 8) were in existence throughout this 9-month interval. The zonal scales and amplitudes of these two features both increased substantially at the beginning of January; otherwise, their properties remained fairly constant with time.

The warm-anomaly feature that propagated over the FASINEX moorings had a large influence on the upper ocean heat content. A time series of the heat content at $28^{\circ} \mathrm{N}$ (Figure 10) along the ship-of-opportunity path (Figure 1) between the surface and a depth just beneath the layer significantly influenced by the seasonal cycle $(160 \mathrm{~m})$ shows that the seasonal cycle dominated as expected from June 1984 to December 1985, with the largest (smallest) heat content occurring at the end of summer (winter). However, the passage of the warm-anomaly feature during the FASINEX winter caused the heat content to reach the levels observed during the previous two summers. This heat content was anomalously large during winter 1986 because isotherms in the seasonal thermocline were displaced downward by up to $60 \mathrm{~m}$ (Halliwell, submitted manuscript, 1991), and because the temperature within the mixed layer was about $1^{\circ} \mathrm{C}$ warmer than normal during this winter [Halliwell 


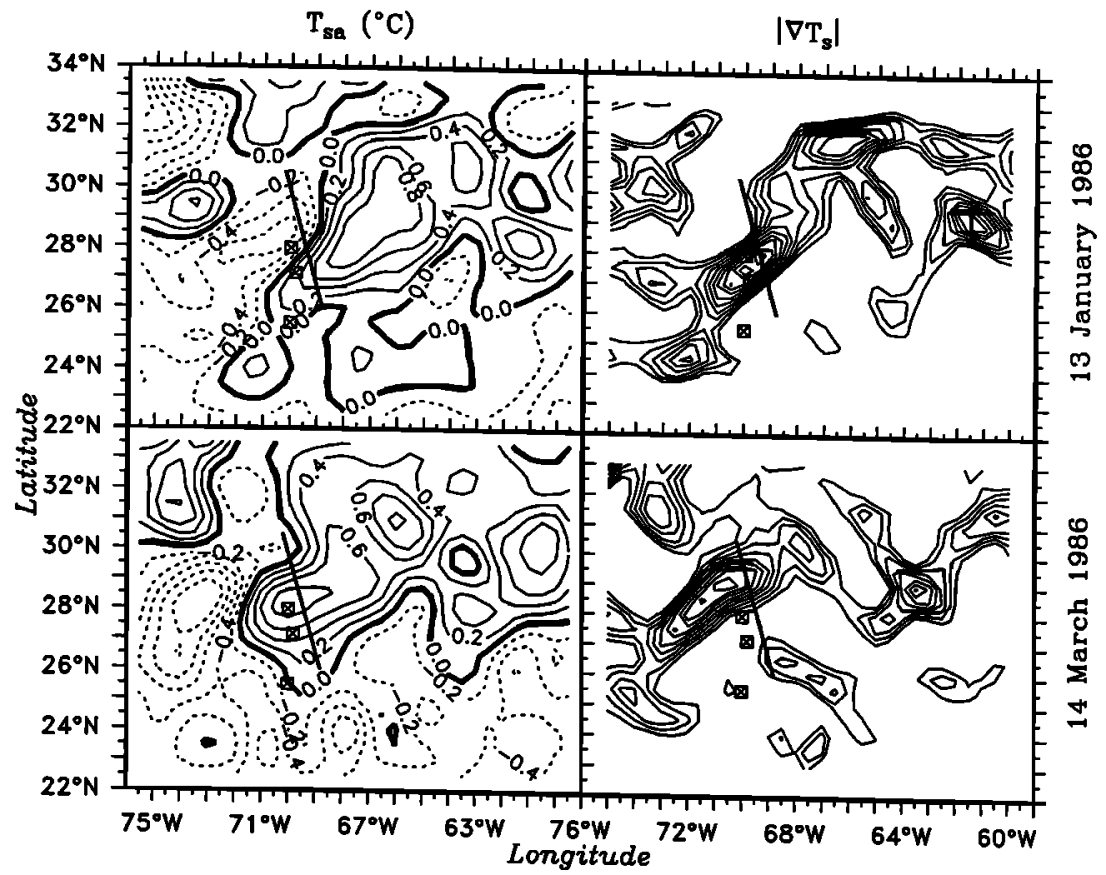

Fig. 8. Maps of $T_{s a}^{\prime}$ and $\left|\nabla T_{s}\right|$ for January 13 and March 14, 1986, calculated using the $T_{s}$ maps created for the long-term analyses (section 3.1) and contoured within the long-term analysis domain (Figure 1). A minimum contour threshold was set for $\left|\nabla T_{s}\right|$ to outline only the stronger frontal bands. The locations of FASINEX moorings (top) F1, (center) F2-F10, and (bottom) F12 are shown by the squares in each panel. The primary ship-of-opportunity track (Halliwell, submitted manuscript, 1991) is shown by the solid straight lines.

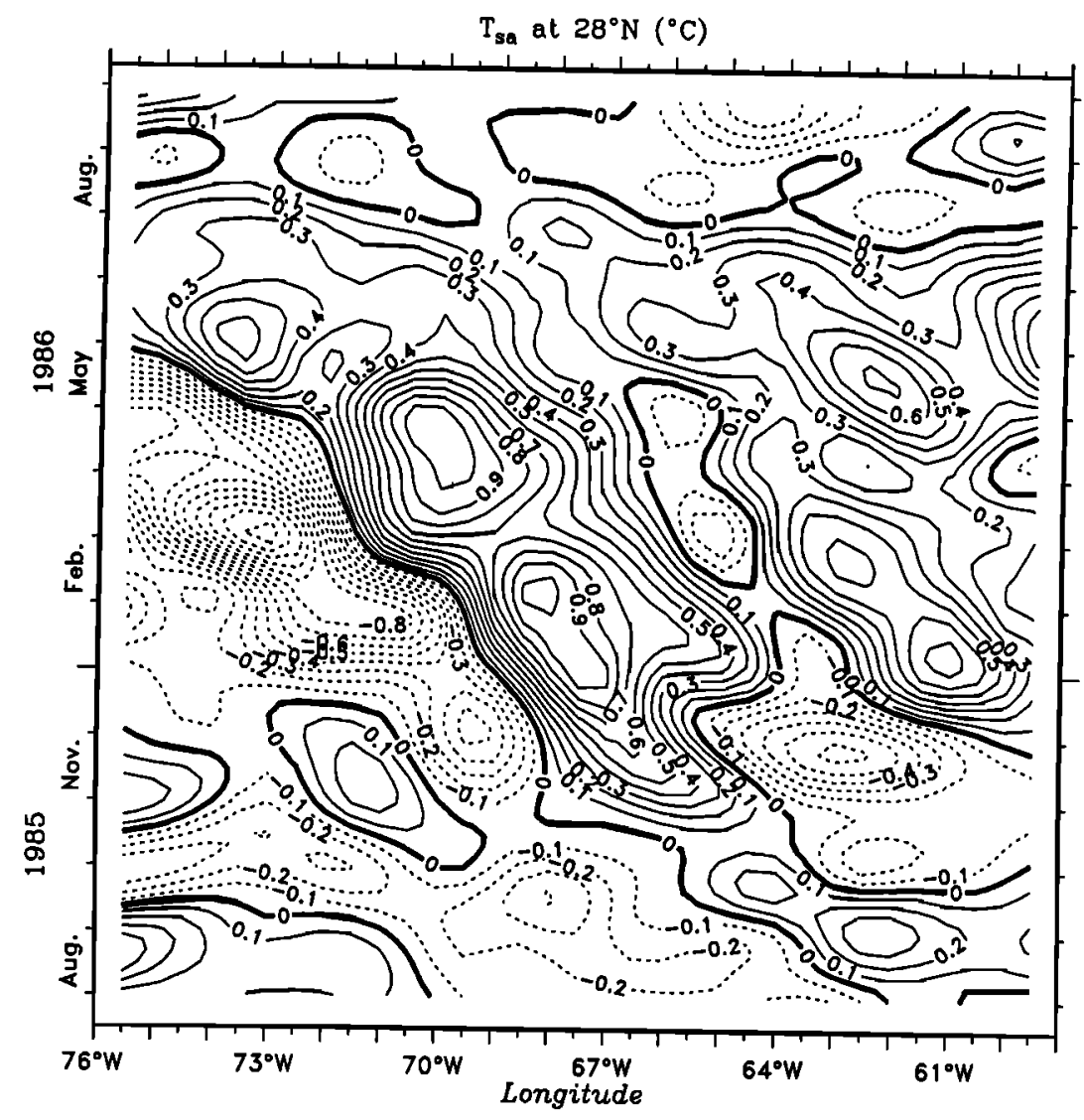

Fig. 9. Contour plot of $T_{s a}^{\prime}\left(x, y_{0}, t\right)$ at $y_{0}=28^{\circ} \mathrm{N}$ from August 1985 through September 1986, calculated using the $T_{s}$ maps created for the long-term analyses (section 3.1 ). 


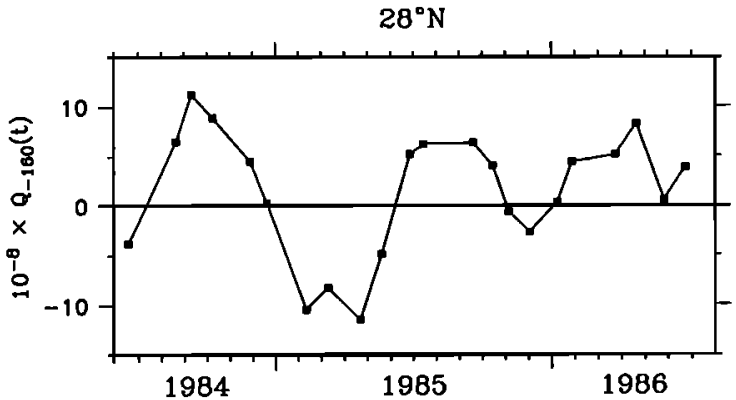

Fig. 10. The total heat content above a depth of $160 \mathrm{~m}\left[Q_{-160}\right.$ $(t)]$, the approximate depth below which the seasonal cycle was not felt, between mid-1984 and mid-1986, graphed with the mean value removed. Estimates of the heat content are shown for the times of 22 XBT cross sections analyzed by Halliwell (submitted manuscript, 1991).

and Cornillon, 1989] and more than $2^{\circ} \mathrm{C}$ warmer than it was during the previous winter.

The typicality of these westward propagating surface anomaly features was assessed by Halliwell et al. (submitted manuscript, 1991). Propagating features were not evident during any of the summers between 1982 and 1988. They appeared during fall and persisted up to several months, with 1981-1982 and 1985-1986 (FASINEX) being the two seasons with the longest persistence (over 7 months for some individual anomaly features). The shortest persistence occurred during 1984-1985, when individual features persisted for only 1-2 months. The features were anisotropic, except during one year (1986-1987), and they had wavelengths between 700 and more than $1200 \mathrm{~km}$ in the minor axis direction (which ranged between E-W and NW-SE from year to year) and periods between 175 and 275 days. To the east of $71^{\circ} \mathrm{W}$, away from the western boundary influence, they propagated almost due westward at $3-4 \mathrm{~km} \mathrm{~d}^{-1}$. They were primarily confined between $26^{\circ}$ and $32^{\circ} \mathrm{N}$, which is illustrated here by displaying two-dimensional longitudetime autocorrelation functions of $T_{s a}^{\prime}\left(x, y_{0}, t\right)$ at three different latitudes $y_{0}\left(33^{\circ}, 28^{\circ}\right.$, and $\left.23^{\circ} \mathrm{N}\right)$. The highly elongated central positive correlation peak at $28^{\circ} \mathrm{N}$ (Figure 11) reveals the dominance of westward phase propagation at that latitude. In contrast, westward phase propagation is only slightly evident at $33^{\circ} \mathrm{N}$ and is not evident at all at $23^{\circ} \mathrm{N}$.

\subsection{Anomaly Forcing by Baroclinic Eddies}

The relationship between baroclinic eddies and $T_{s}$ anomalies was quantified by Halliwell et al. (submitted manuscript, 1991), using a set of $\boldsymbol{\eta}^{\prime}$ maps produced by removing the linear trend from each $\eta$ map. The fact that these eddies are baroclinic was verified by Halliwell [1991] using the FASINEX ship-of-opportunity XBT data and supported by zonal-time autospectra of $\boldsymbol{\eta}^{\prime}$ presented by Halliwell et al. (submitted manuscript, 1991). The statistical coupling between eddies and anomalies from November 1986 to October 1988 is illustrated using zonal time correlation analysis of $T_{s a}^{\prime}$ and $\eta^{\prime}$ at $28.5^{\circ} \mathrm{N}$ (Figure 12), which was the latitude of maximum correlation between the two fields. The two autocorrelation functions are very similar in structure, indicating that variability in both fields is dominated by the same wavelengths, periods, and westward propagation speeds. The cross-correlation function also has very similar struc- ture, but the central positive correlation ridge, which contains statistically significant (to $95 \%$ confidence) correlation values, is displaced toward negative space and time lags. This displacement is consistent with warm (cold) anomalies being located to the west (east) of topographic highs, where warm (cold) water is being meridionally advected across $28.5^{\circ} \mathrm{N}$ by the eddies.

Halliwell et al. (submitted manuscript, 1991) demonstrated that forcing by horizontal eddy geostrophic currents accounted for many of the observed properties of the anomaly response. They demonstrated that the relatively large anomaly response between $26^{\circ}$ and $32^{\circ} \mathrm{N}$ was partly due to the relatively large mean negative $T_{s y}$ there. They also demonstrated that other factors contributed to the confinement of the westward propagating anomalies between $26^{\circ}$ and $32^{\circ} \mathrm{N}$. First, baroclinic eddy variability at wavelengths of $\approx 800 \mathrm{~km}$ and periods of $\approx 200$ days was also confined to the STCZ. Second, the temporal persistence of eddy features at this wavelength and period was relatively large, so anomalies with this wavelength and period were relatively persistent and thus easier to detect above the noise. Eddy persistence as a function of latitude is illustrated in Figure 13 by the temporal persistence scale, essentially the temporal correlation scale that would be estimated by an observer propagating westward at the phase propagation speed. The "mean" winter SFZ between late 1986 and late 1988 is evident between $26^{\circ}$ and $32^{\circ} \mathrm{N}$, where the mean negative $T_{s}$ gradient is relatively large (Figure 13). The eddy temporal persistence scale within this band is 2-3 times larger than to the north or

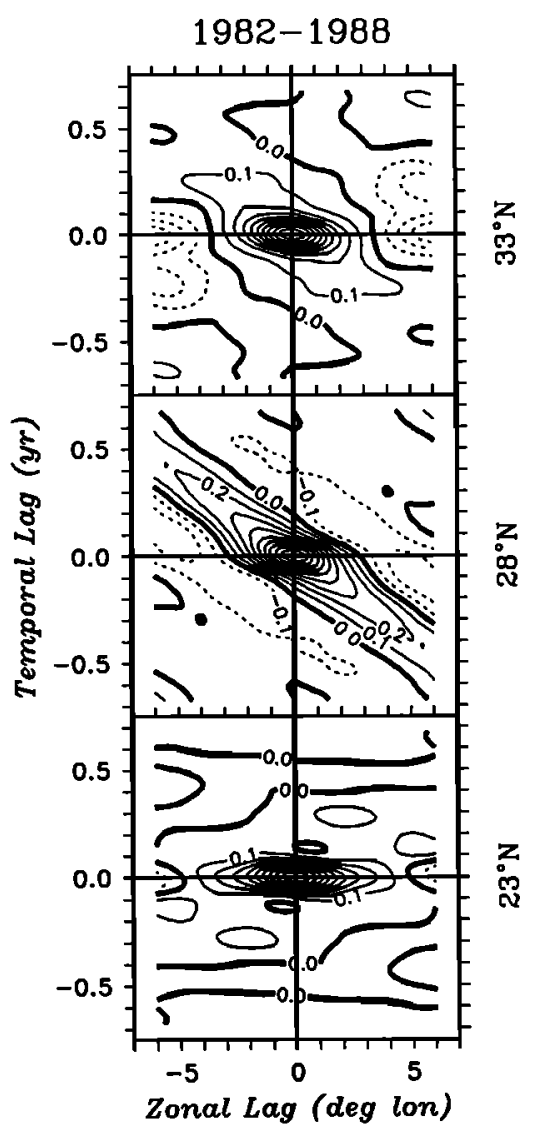

Fig. 11. Zonal-time autocorrelation functions of $T_{s a}^{\prime}\left(x, y_{0}, t\right)$ at $y_{0}=33^{\circ}, 28^{\circ}$, and $23^{\circ} \mathrm{N}$, calculated over the time interval $1982-1988$. 


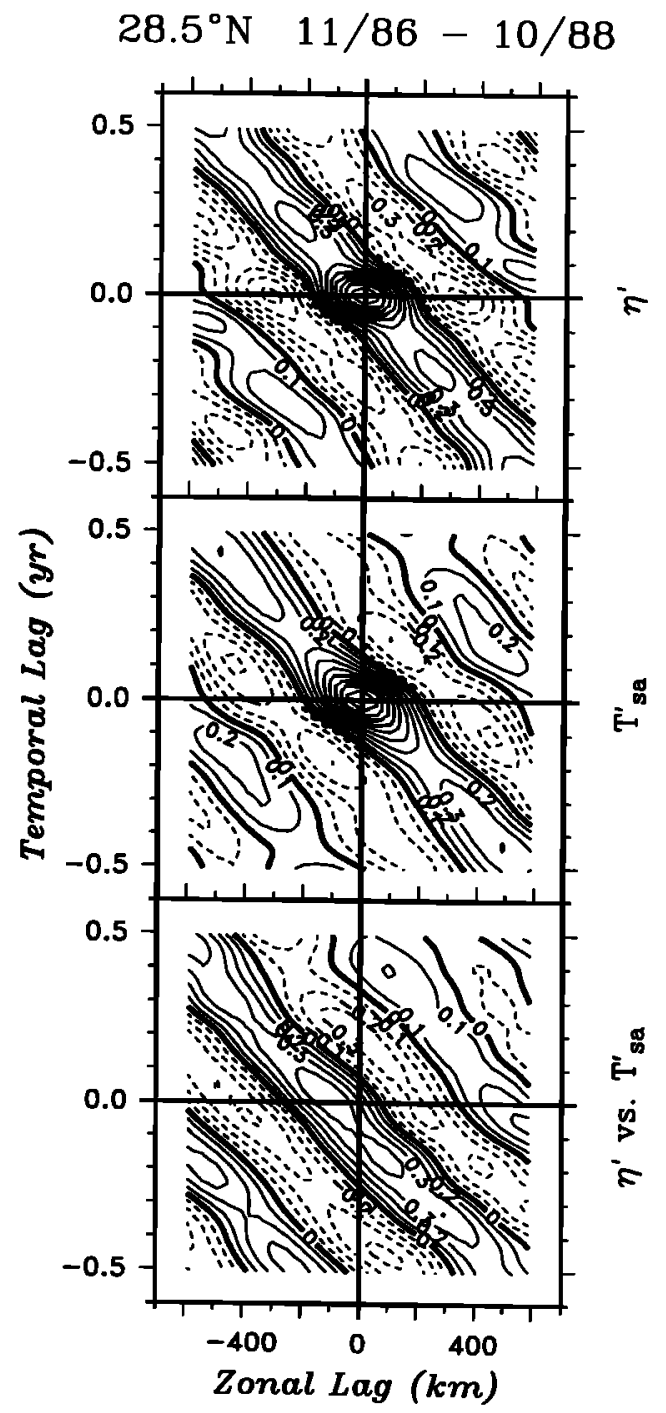

Fig. 12. Zonal-time autocorrelation functions of (top) $T_{s}\left(x, y_{0}\right.$, $t$ ) and (center) $\eta^{\prime}\left(x, y_{0}, t\right)$ (bottom) and the zonal-time crosscorrelation function between $\eta^{\prime}\left(x, y_{0}, t\right)$ and $T_{s}\left(x, y_{0}, t\right)$ at $y_{0}=$ $28.5^{\circ} \mathrm{N}$ over the time interval November 1986 through October 1988. (Adapted from Halliwell et al. (submitted manuscript, 1991, Figure 3)).

south. Also, the westward propagation speed of the eddy field was 2-3 times larger outside of than within the STCZ (Figure 13).

Halliwell et al. (submitted manuscript, 1991) speculated that eddy/mean-current interaction processes may be largely responsible for the observed meridional variability of eddy properties. Shear in the predominantly zonal mean current pattern of the Sargasso Sea (section 2) produces significant meridional variability in the background potential vorticity gradient. Halliwell et al. (submitted manuscript, 1991) demonstrated, using a simple linearized reduced gravity model, that the predicted meridional variability in the zonal dispersion properties of baroclinic Rossby wave modes can qualitatively account for some of the observed meridional variability of eddy properties, primarily for eddy variability with wavelengths exceeding $\approx 500 \mathrm{~km}$. The agreement was primarily limited to longer wavelengths, because nonlinear effects become so dominant at smaller wavelengths that simple linearized models of the interaction between Rossby waves and mean current are no longer relevant. The transition wave number below which wave dynamics becomes dominant over nonlinear dynamics [e.g., Killworth, 1979; Haidvogel, 1983], $k_{T} \approx(\beta / 2 U)^{1 / 2}$, estimated using a characteristic rms amplitude of $0.1 \mathrm{~m} \mathrm{~s}^{-1}$ to represent the current speed $U$ in this region [e.g., Brink, 1989], indicates that the transition wavelength is about $600 \mathrm{~km}$. These dynamics are further discussed by Halliwell et al. (submitted manuscript, 1991). They also discuss other dynamical mechanisms that could produce meridional variability in eddy properties, such as instabilities of the mean current field and Rossby wave refraction due to mean current shear. Considering the latter mechanism, Chang [1990] and Chang and Philander [1990] demonstrate how a predominantly zonal mean current pattern alternating between eastward and westward flow can trap Rossby wave energy within well-defined latitude bands.

Another important question concerns the mechanisms responsible for the mean current pattern within the Sargasso Sea, most specifically the band of mean eastward current. The meridional density gradient pattern due to the existence of the mean SFZ contributes to mean eastward current shear within the upper 100-200 m. However, evidence suggests that other dynamical processes are probably important. For example, eastward mean flow extends downward into the main thermocline, much deeper than the direct influence of meridional Ekman transport on $T_{s}$ and density. Also, the 0to 1000-dbar mean dynamic topography map presented by Olson et al. [1984, Figure 10], along with the 100- to 700-dbar map presented by Stommel et al. [1976, Figure 2], both indicate that the eastward current and associated zonal ridge in dynamic topography to the south could to some extent be considered an extension of the Gulf Stream recirculation. This implies that western boundary processes could be involved in setting up this current. Another possibility is that

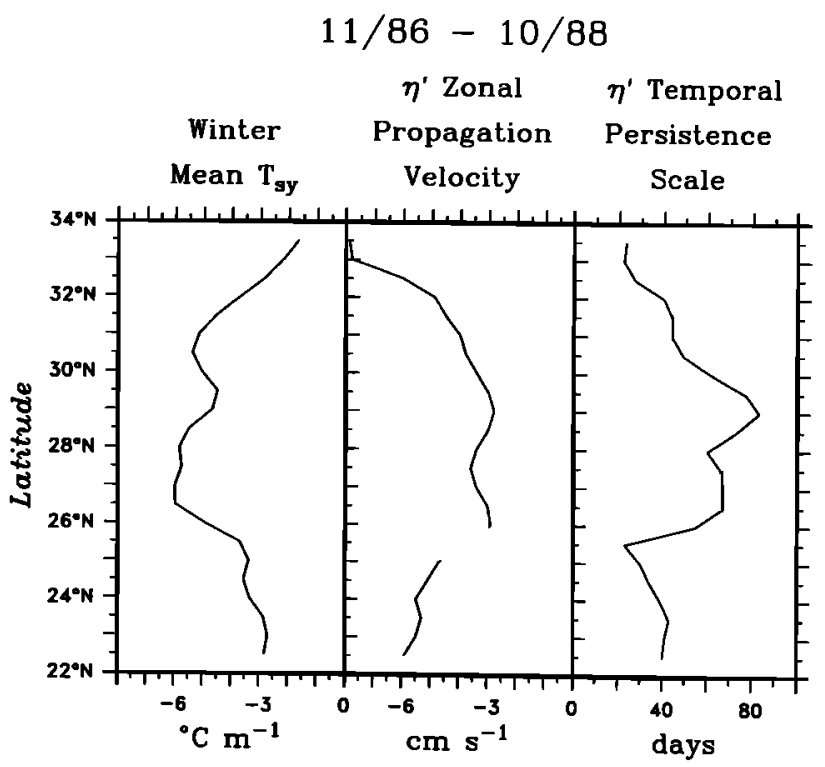

Fig. 13. Meridional profiles of (left) winter mean $T_{s y}$, (center) the zonal phase propagation velocity of $\boldsymbol{\eta}^{\prime}$, and (right) the temporal persistence scale of $\eta^{\prime}$ over the time interval November 1986 through October 1988. The latter two functions were estimated from zonal-time autocorrelation functions of $\eta^{\prime}$, and the gap in zonal propagation velocity at $25.5^{\circ} \mathrm{N}$ occurs because westward phase propagation was nearly undetectable there. 
the eddy field is providing energy to the mean currents. Sorting out these questions will require adequate subsurface data to test appropriate models.

\subsection{Frontal Variability}

In coarse-resolution maps of $T_{s}$, such as in Figure 5, the large-scale SFZ is the only identifiable frontal structure present from fall through spring. The next-finer frontal structures in the Sargasso Sea become visible in contour plots of $\left|\nabla T_{s}\right|$, such as the one for February 1986 presented in Figure 14. Interconnected bands of relatively large $\left|\nabla T_{s}\right|$ are evident that tend to be strongest $\left(\left|\nabla T_{s}\right|\right.$ the largest) within the SFZ. These are essentially the same bands within which the monthly compilation of frontal paths are concentrated (Figure 3). Two steps leading to eventual frontogenesis have thus been identified. The predominantly zonal band of enhanced background $T_{s}$ gradients associated with the SFZ is set up first, in part due to Ekman frontogenesis. Other processes then act to enhance $T_{s}$ gradient magnitude within the interconnected bands.

It is within these bands that strong fronts tend to form. Consequently, the processes responsible for creating the bands of large $\left|\nabla T_{s}\right|$ form a vital link in the formation of subtropical fronts. It is the baroclinic eddies responsible for the propagating $T_{s}$ anomalies between $26^{\circ}$ and $32^{\circ} \mathrm{N}$ that are primarily responsible for producing these organized frontal bands. Comparison of Figures 8 and 14 indicates that the frontal bands tend to be found around the peripheries of the warm- and cold-anomaly features. This pattern is consistent with frontogenesis that arises owing to deformation present in the horizontal eddy current field. Halliwell [1991] estimated that a characteristic deformation rate of $10^{-6} \mathrm{~s}^{-1}$ due to horizontal eddy currents at the $\approx 200-\mathrm{km}$ scales of the frontal bands acted to enhance $T_{s}$ gradient magnitude within the bands. The frontogenesis model of MacVean and Woods [1980] predicts that this deformation rate will lead to the formation of a density discontinuity (front) in 1-2 months, consistent with the observed long periods of frontal band variability. Smaller eddies that can produce deformation rates equaling or exceeding $10^{-5} \mathrm{~s}^{-1}$, and thus can lead to the formation of fronts within a few days [MacVean and Woods, 1980], are undoubtedly responsible for the observed smaller-scale, short-period variability of fronts [e.g., Voorhis et al., 1976; Voorhis and Bruce, 1982; Pollard, 1986;

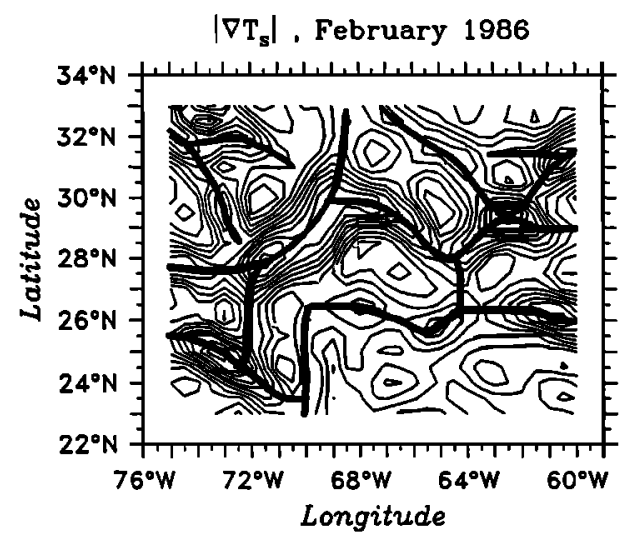

Fig. 14. Map of average $\left|\nabla T_{s}\right|$ February 1986, with ridges of large $\left|\nabla T_{s}\right|$ traced by the thick solid lines, calculated using the $T_{s}$ maps created for the long-term analyses (section 3.1).
Eriksen et al., this issue]. Horizontal current variability due to these smaller eddies will force frontal variability relatively effectively within the frontal bands owing to the larger gradient magnitudes present there. Samelson and Paulson [1988] noted that the influence of eddy variability on upper ocean temperature in the eastern North Pacific SFZ extended down to wavelengths near $10 \mathrm{~km}$. The influence of the atmosphere on frontogenesis appears to be comparatively weak throughout the wave number range of this eddy variability, although as the $O(1)$ to $O(10) \mathrm{km}$ frontal scales are approached, air-sea interaction is modified by the presence of the oceanic fronts [e.g., Friehe et al., this issue; Weller et al., this issue], and may have a potentially significant influence on the fronts at these scales.

The frontal bands tend to propagate with the associated anomaly features, although the propagation of the bands is relatively difficult to follow, since they appear in derivatives of the $T_{s}$ field. To illustrate this, $\left|\nabla T_{s}\right|$ have been contoured in Figure 8 at the times of the corresponding $T_{s a}^{\prime}$ maps, but with a minimum contour level set to outline only the stronger frontal bands. The strongest segments of these bands exist where they separate a warm feature to the south from a cold feature to the north. The strong segment with a SW-NE orientation evident between about $69^{\circ}$ and $72^{\circ} \mathrm{W}$, which contained the strong front across which the FASINEX central mooring array was deployed [Weller, this issue], is evident on January 13. This segment shifted northwestward with time, along with the strong front within it, to be located $\approx 2^{\circ}$ to the north of the central mooring array during FASINEX Phase II, as shown by the March 14 position (Figure 8). This apparent northwestward propagation appears to be related to the westward propagation of the large-scale anomaly features, given the SW-NE orientation of the strong frontal band. The large-scale wind field was not responsible for the propagation of this frontal band. Halliwell and Cornillon [1990b] showed that the large-scale Ekman transport field was acting to shift the fronts near the FASINEX site toward the south on average, not toward the west or northwest as observed.

\subsection{Remote Atmospheric Forcing}

If the $T_{s}$ anomaly features are at least partly driven by an underlying baroclinic eddy field, then remote atmospheric forcing could indirectly influence the surface anomaly field if the underlying eddies are partly driven by this forcing. Eddies can be forced by atmospheric variability in the open ocean [Müller and Frankignoul, 1981; at the eastern boundary [e.g., Cummins et al., 1986], or over the mid-Atlantic ridge [Barnier, 1988].

Observational evidence of remote atmospheric forcing [Brink, 1989] was obtained in the FASINEX region using the long-term FASINEX moorings F1 and F12 (Figure 1). Periods shorter than about $\mathbf{5 0}$ days were resolved in these analyses, so the results do not directly apply to the dominant baroclinic eddies that forced the westward propagating $T_{s}$ anomalies. At these periods, simple models for flat-bottomed oceans predict that the ocean response should consist of barotropic Rossby waves. Price and Rossby [1982] detected variability due to barotropic Rossby waves in the Sargasso Sea with periods of several tens of days using Lagrangian current measurements. However, the current response at F1 and $F 12$ was surface intensified and associated with isotherm 
fluctuations. This was attributed in part to the influence of topography on Rossby wave modes [Brink, 1989]. A simple linear model qualitatively predicted some of the properties of the response but significantly underestimated the amplitude [Brink, 1989]. Similar results were obtained in the eastern North Atlantic by Samelson [1990]. These studies confirm that remote atmospheric forcing will have to be considered in studies of medium- and large-scale oceanic variability.

\section{Summary}

The formation of subtropical fronts was strongly modulated by baroclinic eddies at medium and large scales. The first step toward frontogenesis is the enhancement of meridional $T_{s}$ gradients between about $26^{\circ}$ and $32^{\circ} \mathrm{N}$, due at least in part to Ekman frontogenesis caused by the large-scale "mean" wind stress field. Eddy with wavelengths of $\approx 800$ $\mathrm{km}$ and periods of $\approx 200$ days are relatively effective at forcing $T_{s}$ variability within the STCZ, because this eddy variability is confined to the STCZ and because the large mean meridional $T_{s}$ gradient there allows horizontal eddy currents to force relatively strong anomalies. These eddies generate bands of enhanced $T_{s}$ gradient magnitude that are $\approx 200 \mathrm{~km}$ wide and separated by up to several hundred kilometers through deformation in the horizontal current field. Smaller-scale eddies then exert the dominant influence on frontogenesis and frontolysis within these bands. The eddy-generated bands of enhanced $T_{s}$ gradient magnitude are where strong fronts evident in AVHRR images are most likely to form. Westward propagation of the medium- and large-scale eddy/anomaly/frontal-band pattern exerted a significant influence on FASINEX measurements by producing an apparent northwestward shift of oceanic fronts that had a SW-NE orientation. This orientation, which is noted by Eriksen et al. [this issue], was apparently imposed by the horizontal structure of the eddy-forced $T_{s}$ anomaly features, which were anisotropic during FASINEX, with a SW-NE major axis orientation. The propagation of a warm-anomaly feature past the FASINEX moorings during most of the experiment produced very warm conditions in the upper ocean. Successful theories of the formation and variability of subtropical fronts must consider the influence of the eddy field over a very wide range of wavelengths. The largest eddies that influence frontal variability are themselves apparently influenced by shear in the large-scale mean current pattern, which is itself influenced in part by the mean large-scale meridional density gradients associated with the mean SFZ. At the medium to large scales resolved in the present analyses, frontogenesis involved a complex interaction among the large-scale Ekman transport pattern, the mean current pattern, the oceanic baroclinic eddy field, and the mixed layer. We were only able to test some of the dynamical processes leading to this complex interaction.

Acknowledgments. This research was performed at the University of Rhode Island with the support of the Office of Naval Research (grant N00014-87-KT0235), as part of the FASINEX program. The FASINEX ship-of-opportunity program was sponsored by grant N00014-81-C-0062. All figures except the AVHRR images were generated using the interactive graphics package PLOT5, developed by Donald Denbo. Robert Weller provided data from the FASINEX surface buoys. The FNOC winds were obtained through Jay Morford of FNOC. The image-processing software was developed by R. Evans, O. Brown, J. Brown, and $\mathrm{A}$. Li at the
University of Miami, under Office of Naval Research funding. The continuing support of the Miami group is gratefully acknowledged. The manuscript was extensively revised by G. R. H. at RSMAS, and transitional support provided under grants from NASA (NAGW273, NAGW-678, and NASS-30557) and ONR (N00014-89-J-1144) is gratefully acknowledged. This paper is FASINEX contribution 81.

\section{REFERENCES}

Barnier, B., A numerical study on the influence of the Mid-Atlantic Ridge on nonlinear first-mode baroclinic Rossby waves generated by seasonal winds, J. Phys. Oceanogr., 18, 417-433, 1988.

Böhm, E., Subtropical fronts in the Sargasso Sea: A four-year satellite analysis, M. S. thesis, 61 pp., Univ. of R. I., Narragansett, 1988.

Brink, K. H., Evidence of wind-driven current fluctuations in the western North Atlantic, J. Geophys. Res., 94, 2029-2044, 1989.

Chang, P., Oceanic adjustment in the presence of mean currents on an equatorial $\beta$ plane, J. Geophys. Res., 95, 15,975-15,996, 1990.

Chang, P., and S. G. H. Philander, Rossby wave packets in baroclinic mean currents, Deep Sea Res., 36, 17-37, 1990.

Chiu, C-S., and Y. Desaubies, A planetary wave analysís using the acoustic and conventional arrays in the 1981 ocean tomography experiment, J. Phys. Oceanogr., 17, 1270-1287, 1987.

Cummins, P. F., L. A. Mysak, and K. Hamilton, Generation of annual Rossby waves in the North Pacific by the wind stress curl, J. Phys. Oceanogr., 16, 1179-1189, 1986.

Cushman-Roisin, B., Effects of horizontal advection on upper ocean mixing-A case of frontogenesis, J. Phys. Oceanogr., 11, 13451356, 1981.

Cushman-Roisin, B., On the maintenance of the subtropical front and its associated countercurrent, J. Phys. Oceanogr., 14, 1179$1190,1984$.

Dantzler, H. L., Jr., Potential energy maxima in the tropical and subtropical North Atlantic, J. Phys. Oceanogr., 7, 512-519, 1977.

De Ruijter, W. P. M., Frontogenesis in an advective mixed-layer model, J. Phys. Oceanogr., 13, 487-495, 1983.

De Szoeke, R. A., On the effects of horizontal variability of wind stress on the dynamics of the ocean mixed layer, $J$. Phys. Oceanogr., 10, 1439-1454, 1980.

Ebbesmeyer, C. C., and B. A. Taft, Variability of potential energy, dynamic height, and salinity in the main pycnocline of the western North Atlantic, J. Phys. Oceanogr., 9, 1073-1089, 1979.

Emery, W. J., On the geographical variability of the upper level mean and eddy fields in the North Atlantic and North Pacific, $J$. Phys. Oceanogr., 13, 269-291, 1983.

Eriksen, C. C., R. A. Weller, D. L. Rudnick, R. T. Pollard, and L. A. Regier, Ocean frontal variability in the Frontal Air-Sea Interaction Experiment, J. Geophys. Res., this issue.

Evans, D. L., G. A. Strout, and A. K. Monaghan, FASINEX ship-of-opportunity data report, Tech. Rep., Ref. 86-6, Grad. Sch. of Oceanogr., Univ. of R. I., Narragansett, 1986.

Fedorov, N. K., The physical nature and structure of oceanic fronts, Lect. Notes Coast. Estuar. Stud., vol. 19, translated by N. Demidenko, edited by C. Garrett, 333 pp., Springer-Verlag, Berlin, 1983.

Frankignoul, C., Sea surface temperature anomalies, planetary waves, and air-sea feedback in the middle latitudes, Rev. Geophys., 23, 357-390, 1985.

Friehe, C. A., W. J. Shaw, D. P. Rogers, K. L. Davidson, W. G. Large, S. A. Stage, G. H. Crescenti, S. J. S. Khalsa, G. K. Greenhut, and F. Li, Air-sea fluxes and surface layer turbulence around a sea surface temperature front, J. Geophys. Res., this issue.

Haidvogel, D. B., Periodic and regional models, in Eddies in Marine Science, edited by A. R. Robinson, pp. 404-438, Springer-Verlag, New York, 1983.

Halliwell, G. R., Jr., and P. Cornillon, Large-scale SST anomalies associated with subtropical fronts in the western North Atlantic during FASINEX, J. Mar. Res., 47, 757-775, 1989.

Halliwell, G. R., Jr., and P. Cornillon, Large-scale SST variability in the western North Atlantic subtropical convergence zone during FASINEX, 1, Description of SST and wind stress fields, J. Phys. Oceanogr., 20, 209-222, 1990 a.

Halliwell, G. R., Jr., and P. Cornillon, Large-scale SST variability in the western North Atlantic subtropical convergence zone during 
FASINEX, 2, Upper ocean heat balance and frontogenesis, $J$. Phys. Oceanogr., 20, 223-234, 1990b.

Halliwell, G. R., Jr., P. Cornillon, and D. A. Byrne, Westward propagating SST anomaly features in the Sargasso Sea, 1982-88, J. Phys. Oceanogr., in press, 1991.

Hanson, H. P., P. Cornillon, G. Halliwell, and V. M. Halliwell, Climatological perspectives, oceanographic and meteorological, on variability in the subtropical convergence zone in the northwestern Atlantic, J. Geophys. Res., this issue.

Iselin, C. O. D, A study of the circulation of the western North Atlantic, Pap. Phys. Oceanogr. Meteorol., 4, 1936.

Killworth, P., On the propagation of stable baroclinic Rossby waves through mean shear flow, Deep Sea Res., 26A, 997-1031, 1979.

Levitus, S., Climatological atlas of the world ocean, NOAA Prof. Pap., 13, 173 pp., Natl. Oceanic and Atmos. Admin., Washington, D. C., 1982.

MacVean, M. K., and J. D. Woods, Redistribution of scalars during upper-ocean frontogenesis: A numerical model, J. R. Meteorol. Soc., 106, 293-311, 1980.

MODE Group, The Mid-Ocean Dynamics Experiment, Deep Sea Res., 25, 859-910, 1978.

Müller, P., and C. Frankignoul, Direct atmospheric forcing of geostrophic eddies, J. Phys. Oceanogr., 11 287-308, 1981.

Niiler, P. P., and R. W. Reynolds, The three-dimensional circulation near the eastern North Pacific subtropical front, J. Phys. Oceanogr., 14, 217-230, 1984

Olson, D. B., F. A. Schott, R. J. Zantopp, and K. D. Leaman, The mean circulation east of the Bahamas as determined by a recent measurement program and historical XBT data, J. Phys. Oceanogr., 14, 1470-1487, 1984.

Paduan, J., and R. De Szoeke, Heat and energy balances in the upper ocean at $50^{\circ} \mathrm{N}, 140^{\circ} \mathrm{W}$ during November 1980 (STREX), $J$. Phys. Oceanogr., 16, 25-38, 1986.

Pollard, R., Frontal surveys with a towed profiling conductivity/ temperature/depth measurement package (SeaSoar), Nature, 323, 433-435, 1986.

Price, J. F., and H. T. Rossby, Observations of a barotropic planetary wave in the western North Atlantic, J. Mar. Res., 40, (suppl.), 543-558, 1982.

Reid, J. L., Jr., On the mid-depth circulation and salinity field in the North Atlantic Ocean, J. Geophys. Res., 83, 5063-5067, 1978.

Ro, Y. J., and P. Cornillon, How to reduce the geoid error from GEOSAT altimeter by use of EOF technique, submitted to $J$. Atmos. Oceanic. Tech., 1991.

Robinson, A. R., N. E. Huang, C. D. Leitao, and C. G. Parra, A study of the variability of ocean currents in the northwestern Atlantic using satellite altimetry, J. Phys. Oceanogr., 13, 565-585, 1983.

Roden, G. I., On North Pacific salinity, sound velocity, and density fronts, and their relation to the wind and energy flux fields, $J$. Phys. Oceanogr. 5, 557-571, 1975.

Roden, G. I., On the variability of surface temperature fronts in the western Pacific, as detected by satellite, J. Geophys. Res., 85, 2704-2710, 1980

Roden, G. I., and D. F. Paskausky, Estimation of rates of frontogenesis and frontolysis in the North Pacific Ocean using satellite and surface meteorological data from January $1977, J$. Geophys. Res., 83, 4545-4550, 1978.

Rossby, H. T., S. C. Riser, and A. J. Mariano, The western North Atlantic-A Lagrangian viewpoint, in Eddies in Marine Science, edited by A. R. Robinson, pp. 66-91, Springer-Verlag, New York, 1983.

Samelson, R., Evidence for wind-driven current fluctuations in the eastern North Atlantic, J. Geophys. Res., 95, 11,359-11,368, 1990.

Samelson, R., and C. A. Paulson, Towed thermistor chain observations of fronts in the subtropical North Pacific, J. Geophys. Res., 93, 2237-2246, 1988.

Schroeder, E. H., Average monthly temperatures in the North Atlantic Ocean, Deep Sea Res., 12, 323-343, 1965.

Stommel, H., P. Niiler, and D. Anati, Dynamic topography and recirculation of the North Atlantic, J. Mar. Res., 34, 449-468. 1976

Taft, B. A., E. J. Lindstrom, C. C. Ebbesmeyer, C. Y. Shen, and J. C. McWilliams, Water mass structure during the POLYMODE Local Dynamics Experiment, J. Phys. Oceanogr., 16, 403-426, 1986.

Takeuchi, K., Numerical study of the subtropical front and the subtropical countercurrent, J. Oceanogr. Soc. Jpn., 40, 371-381, 1984

Uda, M., and K. Hasunuma, The eastward subtropical countercurrent in the western North Pacific Ocean, J. Oceanogr. Soc. Jpn., $25,201-210,1969$.

Voorhis, A. D., The horizontal extent and persistence of thermal fronts in the Sargasso Sea, Deep Sea Res., 16 (suppl.), 331-337, 1969.

Voorhis, A. D., and J. G. Bruce, Small-scale surface stirring and frontogenesis in the subtropical convergence of the western North Atlantic, J. Mar. Res., 40 (suppl.), 801-821, 1982.

Voorhis, A. D., and J. B. Hersey, Oceanic thermal fronts in the Sargasso Sea, J. Geophys. Res., 69, 3809-3814, 1964.

Voorhis, A. D., E. H. Schroeder, and A. Leetmaa, The influence of deep mesoscale eddies on the sea surface temperature in the North Atlantic subtropical convergence, J. Phys. Oceanogr., 6, 953-961, 1976.

Welander, P., Mixed layers and fronts in simple ocean circulation models, J. Phys. Oceanogr., II, 148-152, 1981.

Weller, R. A., Overview of the Frontal Air-Sea Interaction Experiment (FASINEX): A study of air-sea interaction in a region of strong oceanic gradients, $J$. Geophys. Res., this issue.

Weller, R. A., D. L. Rudnick, C. C. Eriksen, K. L. Polzin, N. S. Oakey, J. W. Toole, R. W. Schmitt, and R. T. Pollard, Forced ocean response during the Frontal Air-Sea Interaction Experiment, J. Geophys. Res., this issue.

White, W. B., K. Hasunuma, and H. Solomon, Large-scale seasonal and secular-scale variability of the subtropical front in the western North Pacific from 1954-1974, J. Geophys. Res., 83, 4531-4544, 1978.

K. H. Brink, R. W. Schmitt, and J. M. Toole, Department of Physical Oceanography, Woods Hole Oceanographic Institution, Woods Hole, MA 02543

P. Cornillon, Graduate School of Oceanography, University of Rhode Island, Narragansett, RI 02882.

D. L. Evans, Physical Oceanography Program, Code 1122PO, Office of Naval Research, Arlington, VA 22217.

G. R. Halliwell, Jr., Division of Meteorology and Physical Oceanography, Rosenstiel School of Marine and Atmospheric Science, 4600 Rickenbacker Causeway, Miami, FL 33149.

R. T. Pollard, Deacon Laboratory Institute of Oceanographic Sciences, Wormley, Godalming, Surrey, GU8 5UB, England.

L. A. Regier, Scripps Institution of Oceanography, A-030, University of California, San Diego, La Jolla, CA 92093.

(Received July 3, 1990; revised January 10, 1991; accepted January 10, 1991.) 